OPEN ACCESS

Edited by:

Dieter Blottner,

Charité Medical University of Berlin,

Germany

Reviewed by:

Sonia Julia-Sanchez,

Ministerio de Educación, Cultura y

Deporte, Spain

Reed Wasson Hoyt,

US Army Research Institute of Environmental Medicine

(USARIEM), United States

*Correspondence:

Wolfgang Schobersberger wolfgang.schobersberger@ tirol-kliniken.at

†These authors have contributed equally to this work

Specialty section

This article was submitted to Environmental, Aviation and Space

Physiology,

a section of the journal

Frontiers in Physiology

Received: 08 June 2018 Accepted: 28 March 2019 Published: 16 April 2019

Citation:

Dünnwald T, Gatterer $H$,

Faulhaber $M$, Arvandi $M$ and Schobersberger W (2019) Body

Composition and Body Weight Changes at Different Altitude Levels:

A Systematic Review and Meta-Analysis.

Front. Physiol. 10:430.

doi: 10.3389/fphys.2019.00430

\section{Body Composition and Body Weight Changes at Different Altitude Levels: A Systematic Review and Meta-Analysis}

\author{
Tobias Dünnwald ${ }^{1+}$, Hannes Gatterer ${ }^{2 \dagger}$, Martin Faulhaber ${ }^{3}$, Marjan Arvandi ${ }^{4}$ and \\ Wolfgang Schobersberger ${ }^{1,5 *}$
}

${ }^{1}$ Institute for Sports Medicine, Alpine Medicine \& Health Tourism, UMIT - University for Health Sciences, Medical Informatics and Technology, Hall in Tirol, Austria, ${ }^{2}$ Institute of Mountain Emergency Medicine, EURAC Research, Bolzano, Italy, ${ }^{3}$ Department of Sport Science, University of Innsbruck, Innsbruck, Austria, ${ }^{4}$ Institute of Public Health, Medical Decision Making and HTA, Department for Public Health, Medical Decision Making and Health Technology Assessment, UMIT University for Health Sciences, Medical Informatics and Technology, Hall in Tirol, Austria, ${ }^{5}$ Tirol Kliniken GmbH Innsbruck, Innsbruck, Austria

Changes in body composition and weight loss frequently occur when humans are exposed to hypoxic environments. The mechanisms thought to be responsible for these changes are increased energy expenditure resulting from increased basal metabolic rate and/or high levels of physical activity, inadequate energy intake, fluid loss as well as gastrointestinal malabsorption. The severity of hypoxia, the duration of exposure as well as the level of physical activity also seem to play crucial roles in the final outcome. On one hand, excessive weight loss in mountaineers exercising at high altitudes may affect performance and climbing success. On the other, hypoxic conditioning is presumed to have an important therapeutic potential in weight management programs in overweight/obese people, especially in combination with exercise. In this regard, it is important to define the hypoxia effect on both body composition and weight change. The purpose of this study is to define, through the use of meta-analysis, the extent of bodyweight -and body composition changes within the three internationally classified altitude levels (moderate altitude: 1500-3500 m; high altitude: 3500-5300 m; extreme altitude: $>5300 \mathrm{~m}$ ), with emphasis on physical activity, nutrition, duration of stay and type of exposure.

Keywords: weight loss, body composition, high altitude, nutrition, hypoxia, exercise

\section{INTRODUCTION}

Short- as well as long-term exposure to hypoxic environments cause comprehensive physiological alterations (Swenson and Bärtsch, 2014). Both normobaric (i.e., simulated altitude) and hypobaric (i.e., real and simulated altitude) hypoxia can lead to a lower partial pressure of oxygen in blood and tissues. As an acute compensatory response, ventilation increases and sympathetic activation causes an altitude dependent increase in cardiac output in lowlanders exposed to high altitude (Baggish and Wolfel, 2014). Hyperventilation is one of the most important factors for ensuring oxygen supply to the tissue. Peripheral chemoreceptors, located in the carotid bodies, respond to 
reductions in arterial partial pressure of oxygen. When a fall in $\mathrm{SaO}_{2}$ is detected, signals stimulate ventilation and lead to sympathetic activation (Kara et al., 2003), hence increasing metabolic demands. In dry and cold environments, the increased ventilation may be accompanied by increased loss of water (i.e., insensible water loss) (Kayser, 1994). These ventilatory and cardiovascular responses ensure that metabolic demands of organs and tissues are met at rest and during exercise at acute altitudes. During sustained hypoxia, cardiac output decreases to levels approaching normoxia. This adaptive response is facilitated by stimulated erythropoiesis, increases in red cell mass as well as by further increases in ventilatory response to hypoxia (Baggish and Wolfel, 2014). In addition to these adaptations, hypoxic environments are frequently shown to influence a person's body composition (e.g., reductions in body weight, fat free mass (FFM), fat mass (FM), muscle mass (MM) and/or body water) (Hamad and Travis, 2006).

Proposed factors responsible for these changes in body composition vary but mainly include an increased basal metabolic rate (BMR) and a negative energy balance (i.e., mismatch of energy intake and energy expenditure) (Kayser and Verges, 2013) (Figure 1). Loss in body water may arise from inadequate water intake, hyperventilation or insensible water loss (respiratory and surface water loss) (Kayser, 1994; Gatterer et al., 2013). A decrease in plasma volume is supposed to arise from reduced activity of aldosterone and increased atrial natriuretic peptide concentration, leading to enhanced fractional Na-excretion and "high altitude diuresis" (Siebenmann et al., 2017). However, water retention at altitude may also contribute to hyperhydration and weight gain, at least during the first days at altitude (Gatterer et al., 2013). The increased BMR is most pronounced during acute hypoxia (Brooks, 2014) and less so during prolonged exposure (Hannon and Sudman, 1973; Butterfield et al., 1992). A higher initial BMR has been related to increased sympathetic activity with higher catecholamine levels during the first days of exposure (Mawson et al., 2000; Kayser and Verges, 2013), that is influenced by the degree of hypoxia (Butterfield et al., 1992). Sympathetic activity is attenuated during longer exposures to high altitude, resulting in diminished BMR. Acute increases in BMR might also be explained by the stress of an initial energy deficit, whereas the decline in BMR during prolonged stays could depend, at least in part, on personal fitness, such that those with a higher fitness level will experience larger reductions in direction to baseline levels (Mawson et al., 2000). In addition to an increased BMR, at least at altitudes above $5000 \mathrm{~m}$, a negative energy balance may result from a reduced energy intake due to either a reduced appetite (Westerterp-Plantenga et al., 1999) or, in part, by impaired intestinal function (Hamad and Travis, 2006). In order to negate loss of heat and maintain body temperature in cold environments, an additional increase in energy expenditure may arise due to involuntary shivering (nonshivering thermogenesis), which is activated to increase heat production and involves depletion of fat storages (Burtscher et al., 2018). Moreover, increased energy expenditure during extensive high-altitude hiking could be responsible for a negative energy balance leading to changes in body composition (Westerterp et al., 1992; Hamad and Travis, 2006; Kayser and Verges, 2013).
It follows then that, in addition to energy balance and activity level, the degree of hypoxia seems to play an obvious role in body composition changes at different altitudes. For instance, reports indicate that body weight loss is a function of the absolute altitude level, and further depends on the duration of the stay, individual adaptation to hypoxia, daily variations in body mass, hydration and type of exposure (Kayser, 1994). Additionally, muscle wasting seems to ensue predominantly at altitudes exceeding $5000 \mathrm{~m}$, whereas catabolic mechanisms may be of minor importance at moderate altitudes with exposure to lower levels of hypoxia (D'Hulst and Deldicque, 2017). Muscle catabolism, which may lead to muscle wasting, can be observed during adaptation to hypoxic exposures when a focus is on restricting the effect of decreased oxygen delivery (Favier et al., 2015). Reductions in muscle mass may lessen BMR (Rolfe and Brown, 1997) and, in addition, are purported to lead to a reduced oxygen diffusion distance that corrects the effect of a decreased oxygen supply to the muscle fibers, both of which illustrates a protective mechanism for ensuring oxygen availability. Muscle catabolism may arise due to a negative energy balance resulting from increased energy expenditure, high levels of physical activity and inadequate nutritional intake. After glycogen and fat stores are depleted, protein stores will be catabolized in order to cover energy expenditure (Ocobock, 2017). In addition, inhibition of skeletal muscle protein synthesis and a preference to use muscle mass as an energy source (rather than fat mass) during hypoxia are both potential factors in exacerbating muscle wasting (Murray, 2009).

Despite such findings, the effect of the altitude level (AL) on body composition has not yet been well reviewed. Therefore, this study aims to provide an overview of the influence of $\mathrm{AL}$ on body composition changes. Obviously, it is not possible to completely isolate the influence that altitude alone has on changes in body composition because most studies describe a number of influencing factors. In fact, according to literature, changes in body composition are the culmination of several single contributors (Hamad and Travis, 2006), of which the degree of hypoxia may be one of the most relevant. Therefore, our systematic review takes a meta-analytic and meta-regression approach to focus on body compositional changes as a function of different AL's (i.e., moderate altitude (1500-3500 m) high altitude $(3500-5300 \mathrm{~m})$ and extreme altitude $(>5300 \mathrm{~m})$, as well as taking into account other factors such as duration of stay, active or passive exposure and nutrition.

\section{METHODS - SYSTEMATIC REVIEW}

A systematic literature search was performed in PubMed, The Cochrane Library (central register of controlled trials), Web of Science (Core collection) and EMBASE, and included studies published prior to January 2019. As the present review focuses on altitude dependent variations in body composition, selected abstracts, titles and full texts had to concur with the following inclusion criteria: original research article, available full text, human subjects, English language, hypobaric (simulated altitude or altitude exposure) or normobaric hypoxia, active 


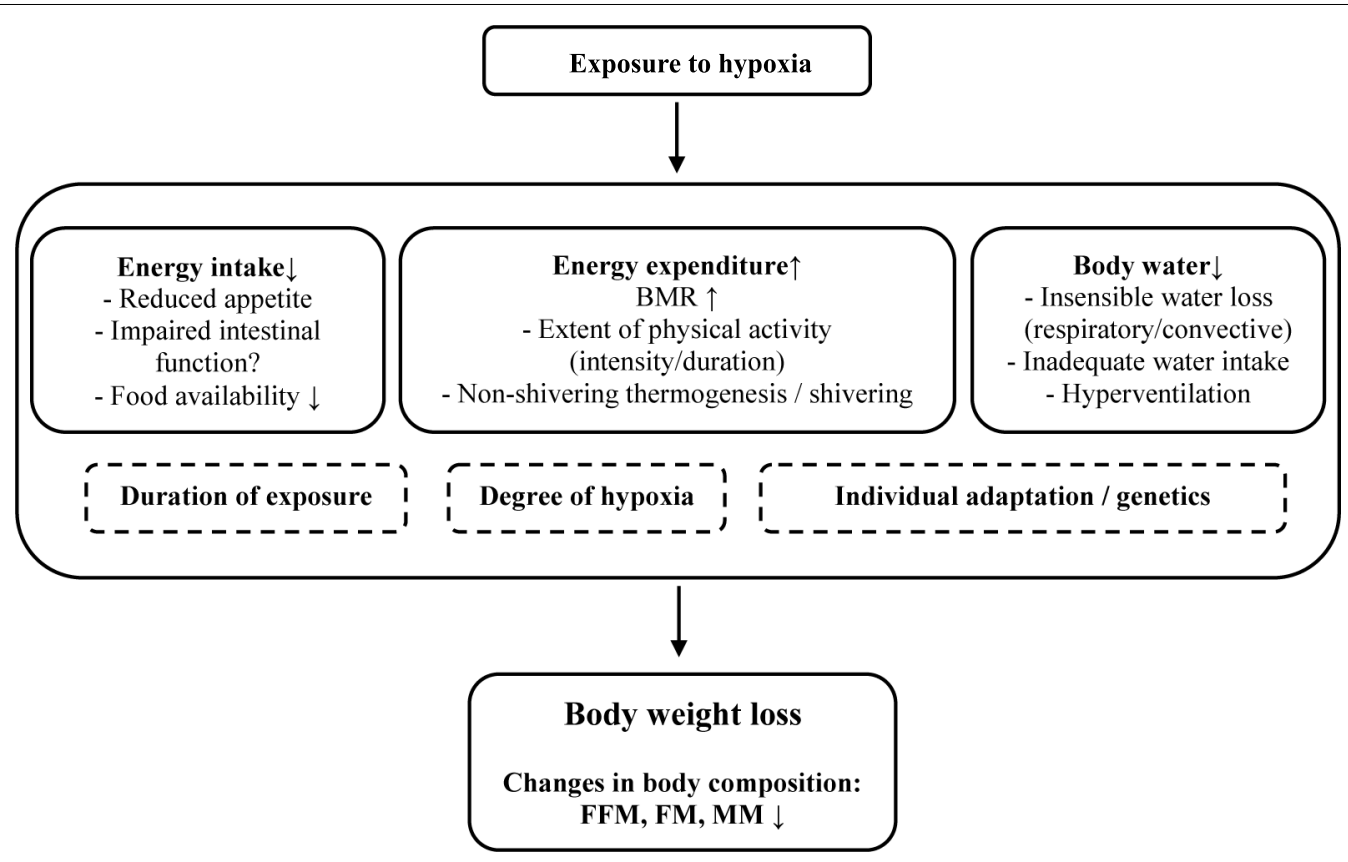

FIGURE 1 | Potential factors being involved in bodyweight and body-composition changes at altitude. BMR, basal metabolic rate; FFM, free fat mass; FM, fat mass; MM, muscle mass.

(exercise) and passive hypoxia, indication of AL, and assessment of at least one of the following parameters: FFM, FM, MM, BMI, body weight or assessment of metabolic response. Exclusion criteria included the absence of information on body composition and/or body weight, studies involving neonates, newborns, high altitude natives or animals, permanent sojourns at altitude and/or disease related hypoxia. The systematic literature search was based on the following search strategy: controlled vocabulary (i.e., MeSH and EMTREE Terms) as well as specific text words (including hypoxia, "altitude training," altitude, "body composition," "fat mass," "body mass," "body weight," "metabolic response," "physiological response," exercise, healthy, overweight, obesity, athlete, patient) were included and systematically combined by the use of Boolean operators (AND/OR).

\section{STUDY SELECTION}

In total, 6395 studies were found in the initial search and screened for relevant titles by two researchers (HG, MF) independently. After excluding 6282 articles by title (including duplicates), the abstracts of the remaining 113 studies were screened for relevance. Thereof, 31 fulfilled the inclusion criteria. Articles were removed due to the following criteria: animal studies, studies involving infants, patients with COPD or high altitude natives, content was not relevant for the review, commentaries or reviews, studies involving (endurance) athletes and/or studies implementing short-term (intermittent) exposures $<12 \mathrm{~h} /$ day. Complementary to the data base searches, reference lists of selected review articles (Hamad and Travis, 2006; Westerterp and Kayser, 2006; Hill et al., 2011; Kayser and Verges, 2013; Heinonen et al., 2016; D’Hulst and Deldicque, 2017; Hobbins et al., 2017; Pasiakos et al., 2017) were carefully screened and relevant original articles were included that complied with the determined inclusion criteria $(n=25)$. In addition, another 16 full texts were included by reference list searching of included studies. Articles where it was not possible to assign changes in bodyweight and body-composition to a corresponding altitude level were also excluded $(N=10)$. A flow chart of the search is illustrated in Figure 2. Most of the selected articles involved an uncontrolled before-and-after study design. Overall, 62 studies were included in the qualitative analysis, and 49 were included in the quantitative analysis a s not all studies provided sufficient information needed for a meta-analysis (Tables 1A-C).

\section{RISK OF BIAS}

As the studies dealing with altitude exposure were predominantly performed in the course of mountaineering expeditions, control groups were mostly lacking, and nutritional and physical activity habits were not thoroughly controlled. Therefore, the current study largely reviews outcomes from uncontrolled before-and-after studies with a number of conditions that potentially influence body weight and composition. Thus, other sources of bias could contribute to the absence of blinding of participants and personnel or sample selection (over-representation of trained subjects). These obvious limitations have to be kept in mind during interpretation of the results. 


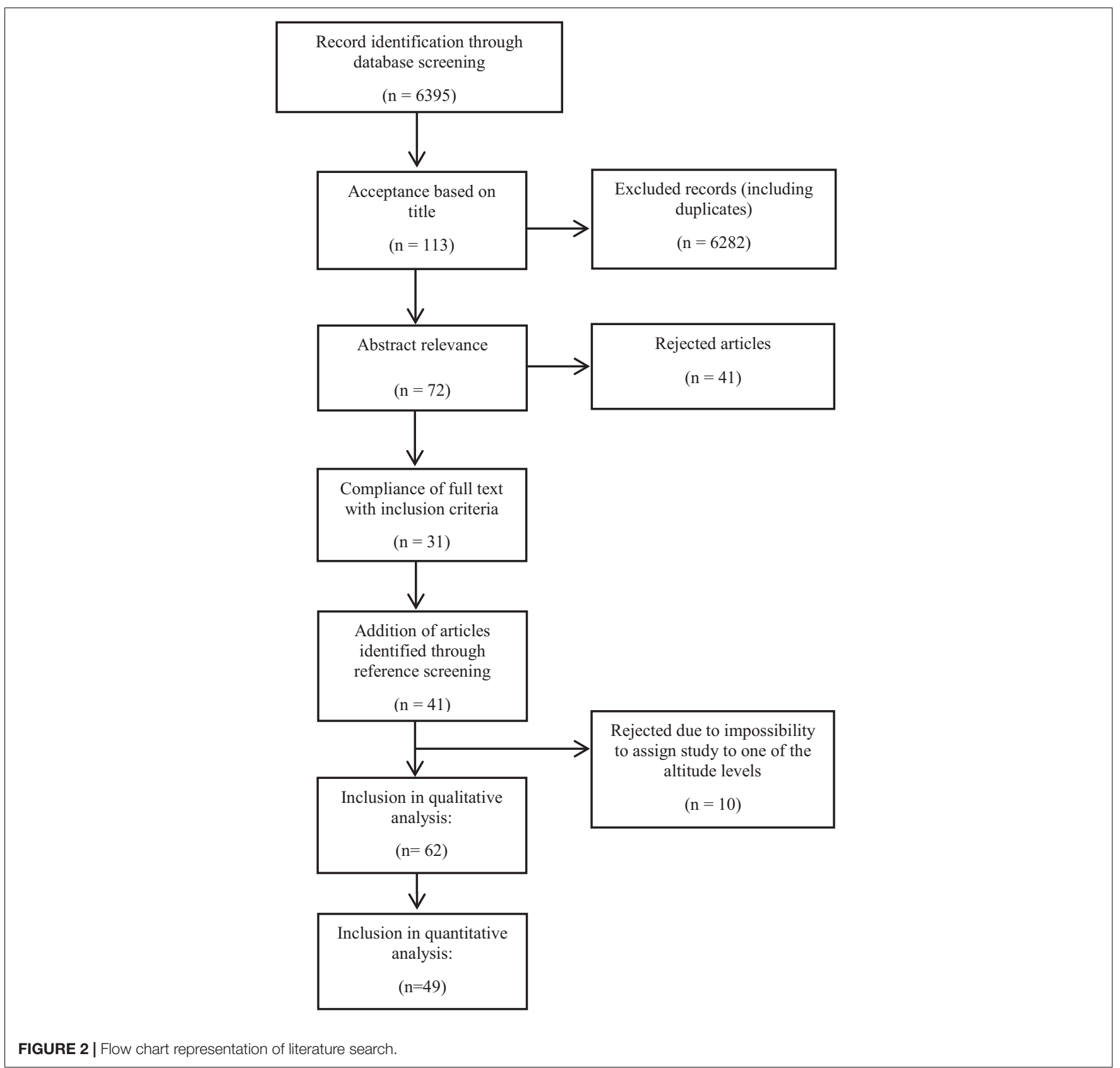

\section{META-ANALYSIS}

Initially, a meta-analysis was performed on data from studies at all altitude levels to evaluate pooled mean changes for each outcome: bodyweight (BW), fat free mass (FFM), fat mass (FM) and muscle mass (MM). In addition, studies were stratified into three main altitude categories according to the main research question (i.e., moderate, high or extreme altitude). Within each category, pooled mean changes in BW, FFM and FM were computed. Furthermore, subgroup meta-analysis was performed for duration of stay, diet, and for active or passive exposure.

If the mean changes in BW, FFM, FM and MM were not reported in the included studies, the value of changes was calculated from the available reported values of before and after BW, FFM, FM and MM. Where standard deviation was quoted instead of standard error, the standard error was recalculated by dividing the standard deviation by the square root of the number of participants in the study.

In each meta-analysis, heterogeneity was quantified by estimation of $I$-squared $\left(I^{2}\right)$ as an indicator of the percentage of variation due to between-study heterogeneity that is not attributed to sampling error (Higgins et al., 2003). Randomand fixed-effects models [DerSimonian and Laird method for random-effects (DerSimonian and Laird, 1986)] were used to calculate pooled mean changes with $95 \%$ confidence intervals (CIs). If the 95\% CIs did not include null, the effect estimates 


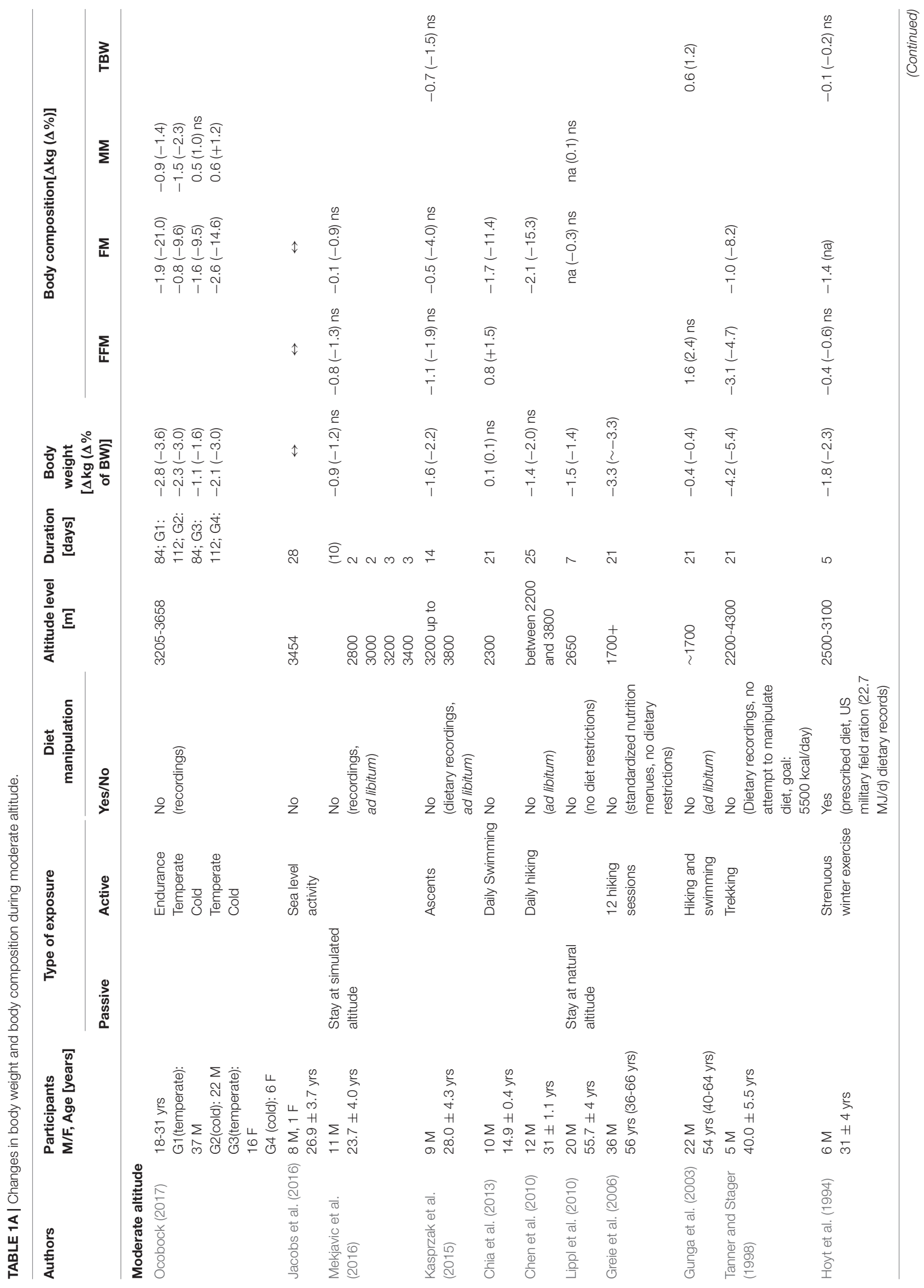




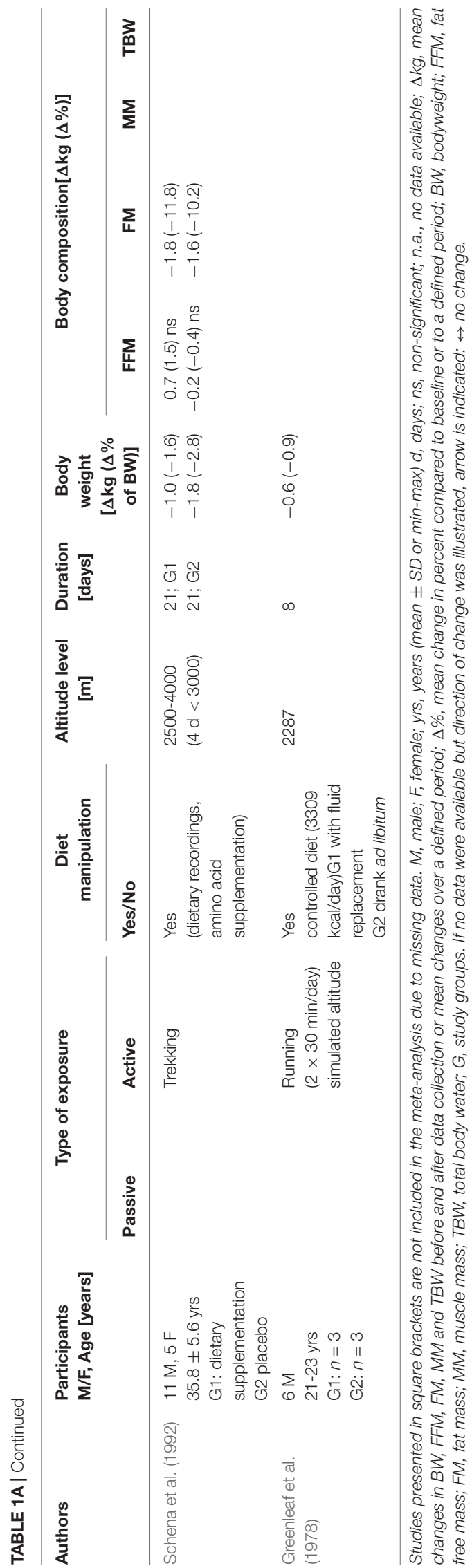

of the meta-analysis were considered significant. In the case of a moderate or high value of $I^{2}$, the first univariate and then multivariate meta-regression (with selected significant variables from the univariate regressions; $p<0.25$ ) were conducted to identify sources of heterogeneity in the effect estimates across studies (Thompson and Higgins, 2002). The following covariates were selected a priori to be included in the meta-regression analysis: baseline bodyweight $(\mathrm{kg})$, altitude (m), duration (days), mean age of the subjects (years), sex, diet (manipulation/non-manipulation of diet/hypocaloric diet) and type of exposure (active/passive). Multivariate metaregression used a residual (restricted) maximum likelihood for the measurement of between-study variance explained with Knapp-Hartung modification (Higgins and Thompson, 2004). In order to detect a publication bias, Begg's funnel plots and the regression test of Egger et al. (1997) were applied.

All the analysis were performed using STATA (StataCorp. 2017. Release 15. College Station, TX, United States: StataCorp LLC).

\section{RESULTS}

The outcomes of the studies are summarized in Tables 1A-C according to the altitude categories: moderate $(n=13,1500-$ $3500 \mathrm{~m})$, high $(n=41,3500-5300 \mathrm{~m})$ and extreme $(n=12$, $>5300 \mathrm{~m}$ ). In addition to AL, Tables $\mathbf{1 A}-\mathrm{C}$ include information on the duration of stay, type and level of physical activity, type of hypoxia and any nutritional intervention. The characteristics of the different altitude stays are outlined below:

\section{Moderate Altitude}

Eleven of the 13 studies (Table 1A) involved physical activity. Active exposure primarily consisted of hiking, trekking and sometimes swimming (e.g., activity during moderate altitude vacations). One of the studies, which incorporated heavy exercise, also manipulated food intake (i.e., US military field ration of 17.66 MJ per day in combination with maltodextrin beverage of 5.02 MJ per day) (Hoyt et al., 1994). The duration of altitude (or simulated altitude) exposure varied from 5 to 112 days (Table 1A). The mean age of the subjects ranged from 23 to 66 years and $87 \%$ of the study subjects were male. The number of subjects varied from 5 to 35 . BW was reported in twelve studies, FFM in six studies, FM in nine studies and MM in two studies.

In the studies that incorporated physical activity, there was a change in body weight of between -4.2 and $+0.1 \mathrm{~kg}$ over an exposure time (ET) of 5 to 112 days. The two studies that investigated resting conditions (Lippl et al., 2010; Mekjavic et al., 2016) showed a weight change of -1.5 to $-0.9 \mathrm{~kg}$ (ET: 7 to 10 days). Manipulating food intake resulted in a weight change of between -1.0 and $-0.6 \mathrm{~kg}$, or up to $-1.8 \mathrm{~kg}$ when combined with heavy military exercise (ET: 5 to 21 days) (Greenleaf et al., 1978; Schena et al., 1992; Hoyt et al., 1994). One study found no reduction in body weight (Chen et al., 2010; Chia et al., 2013). Reductions in FFM were reported to range from -3.1 to $-0.2 \mathrm{~kg}$ whereas increases in FFM ranged from 0.7 to $1.6 \mathrm{~kg}$ (Schena et al., 1992; Gunga et al., 2003; Chia et al., 2013). FM was 


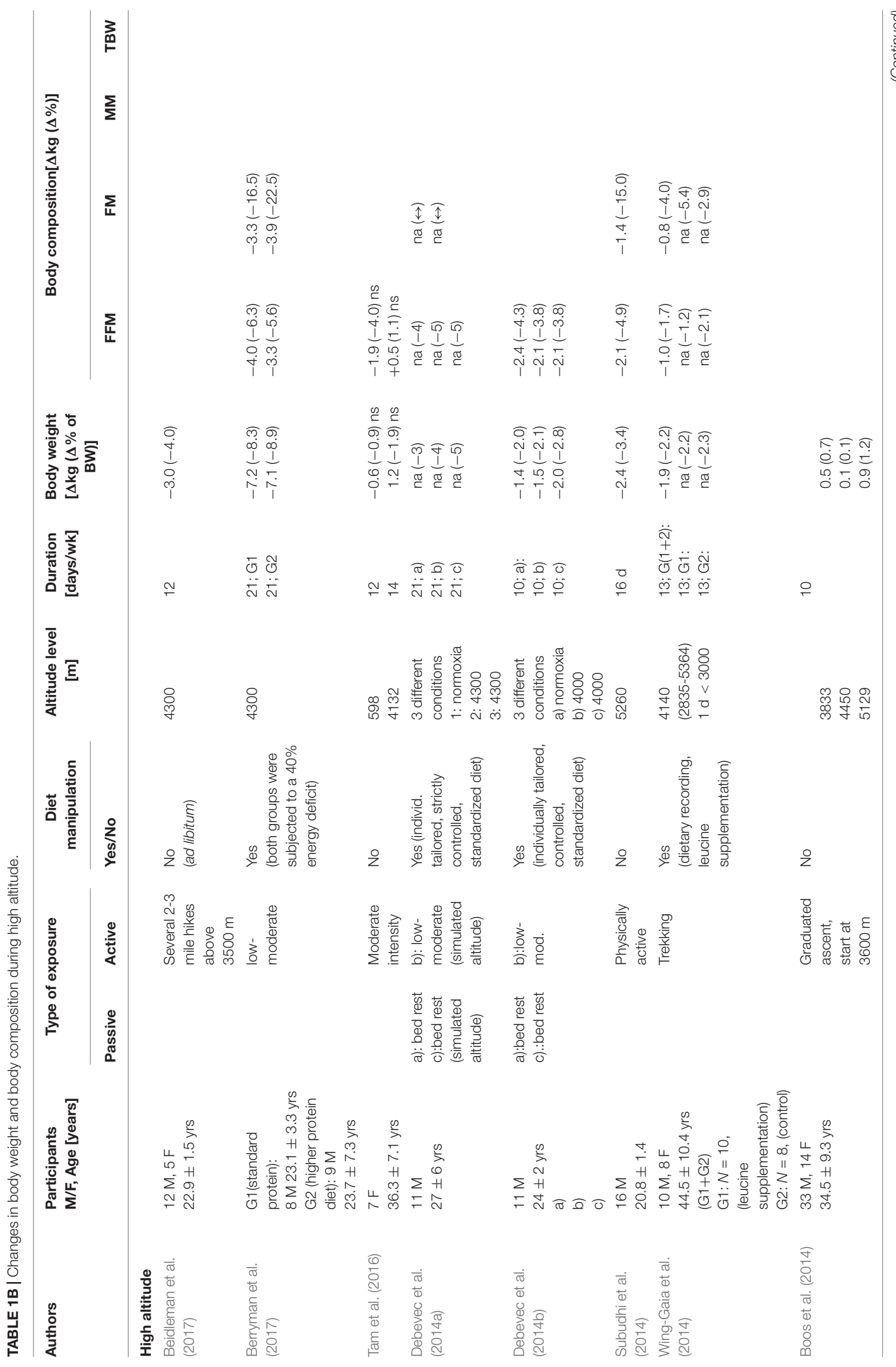




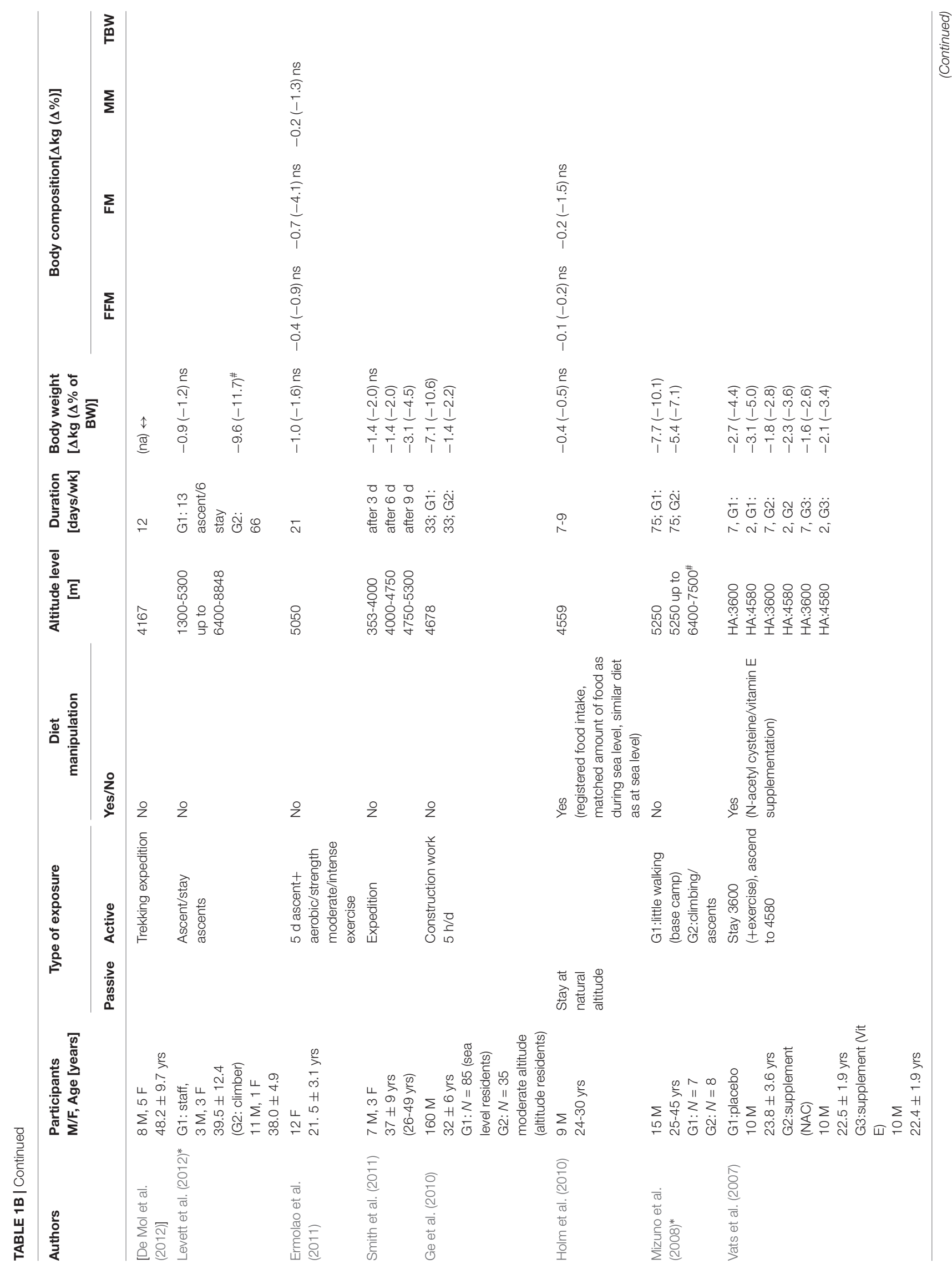




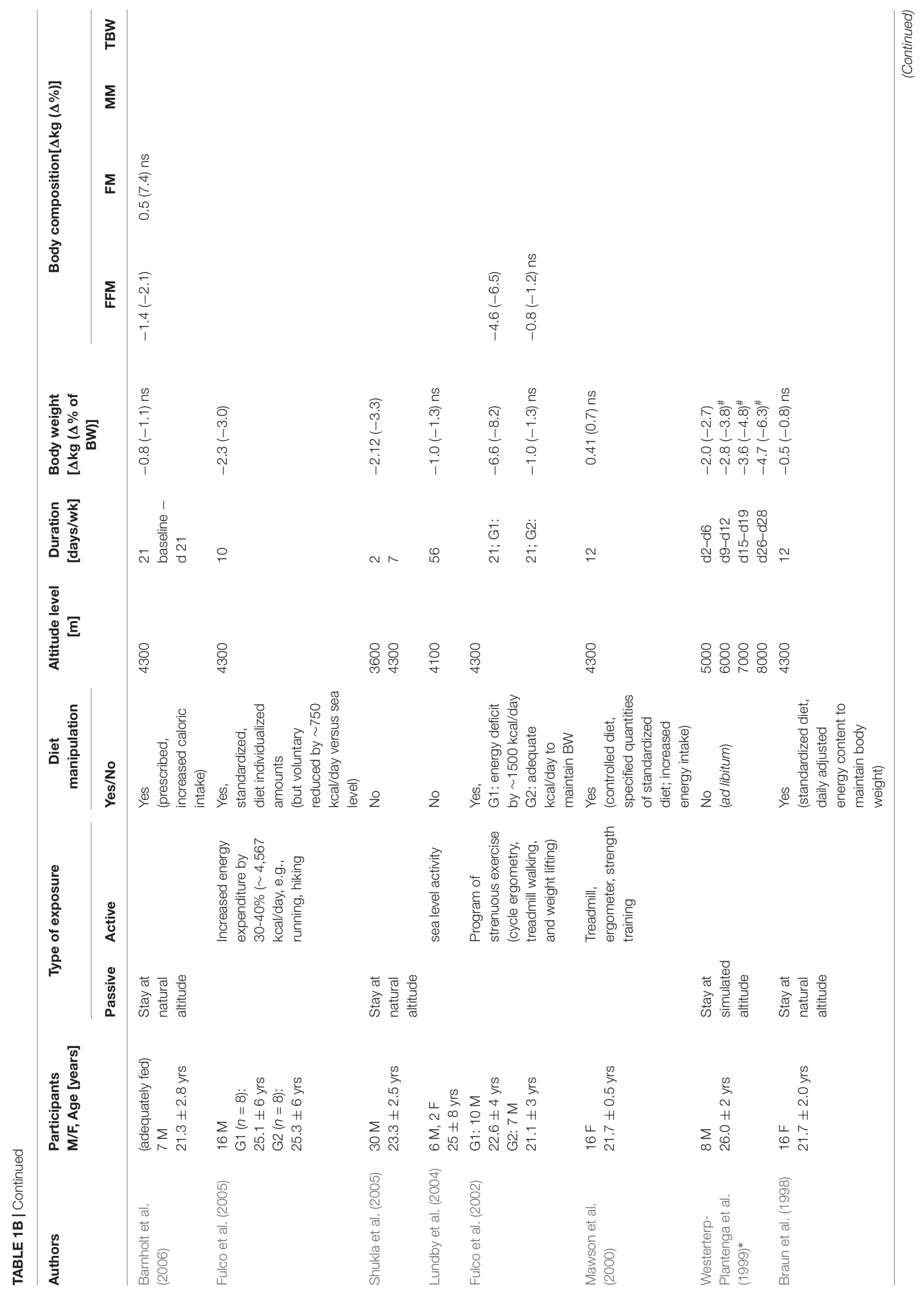




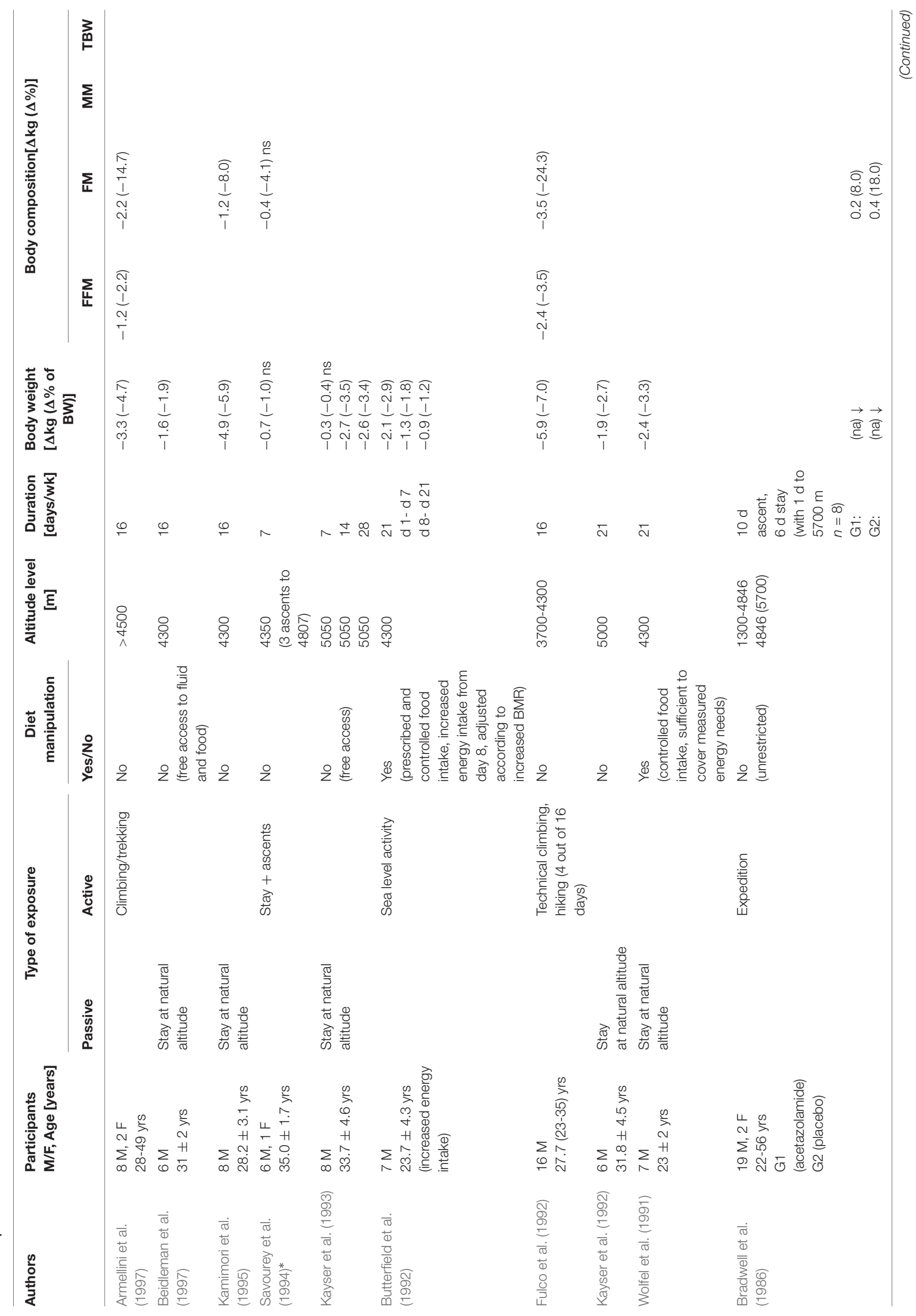




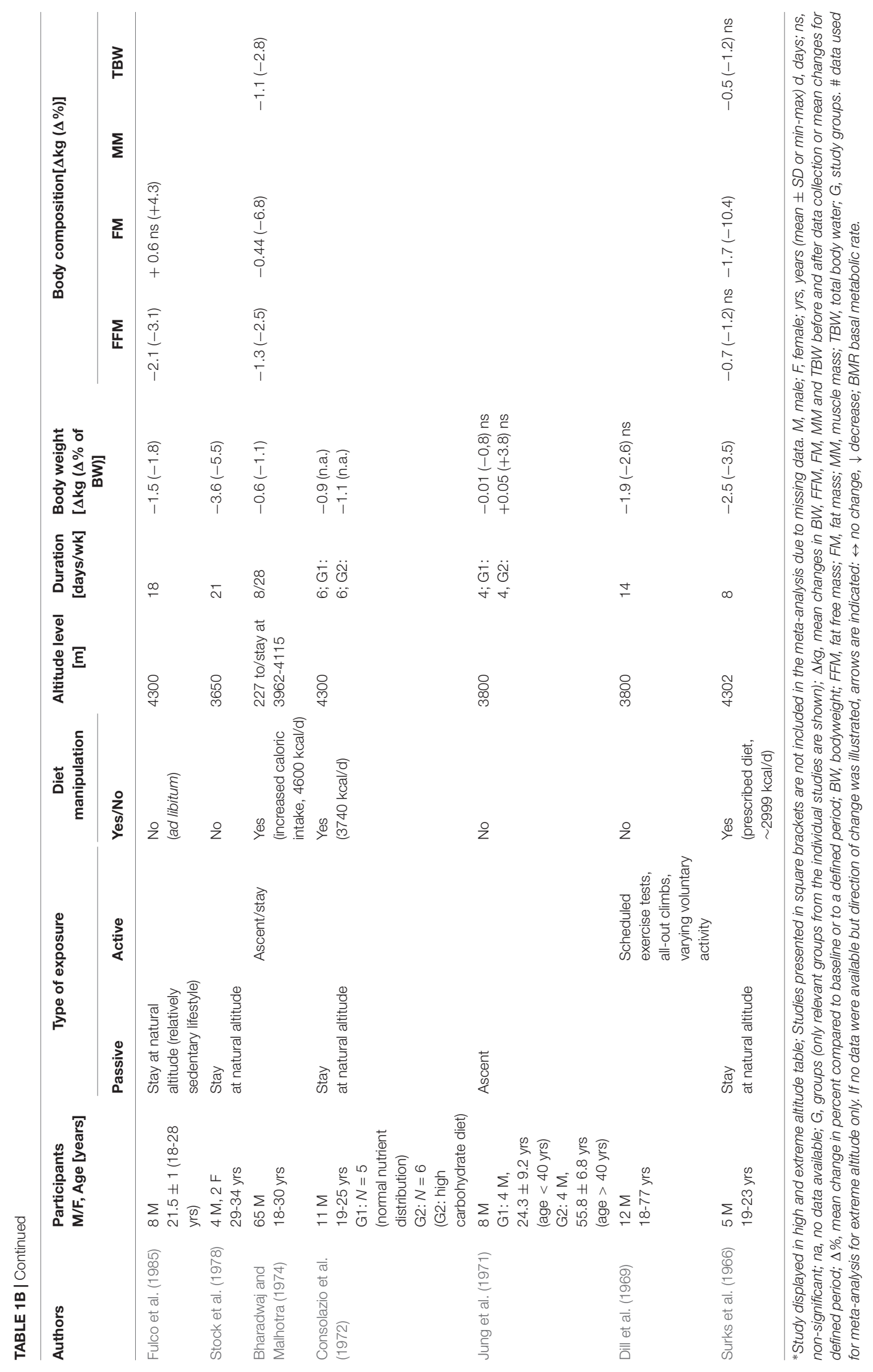




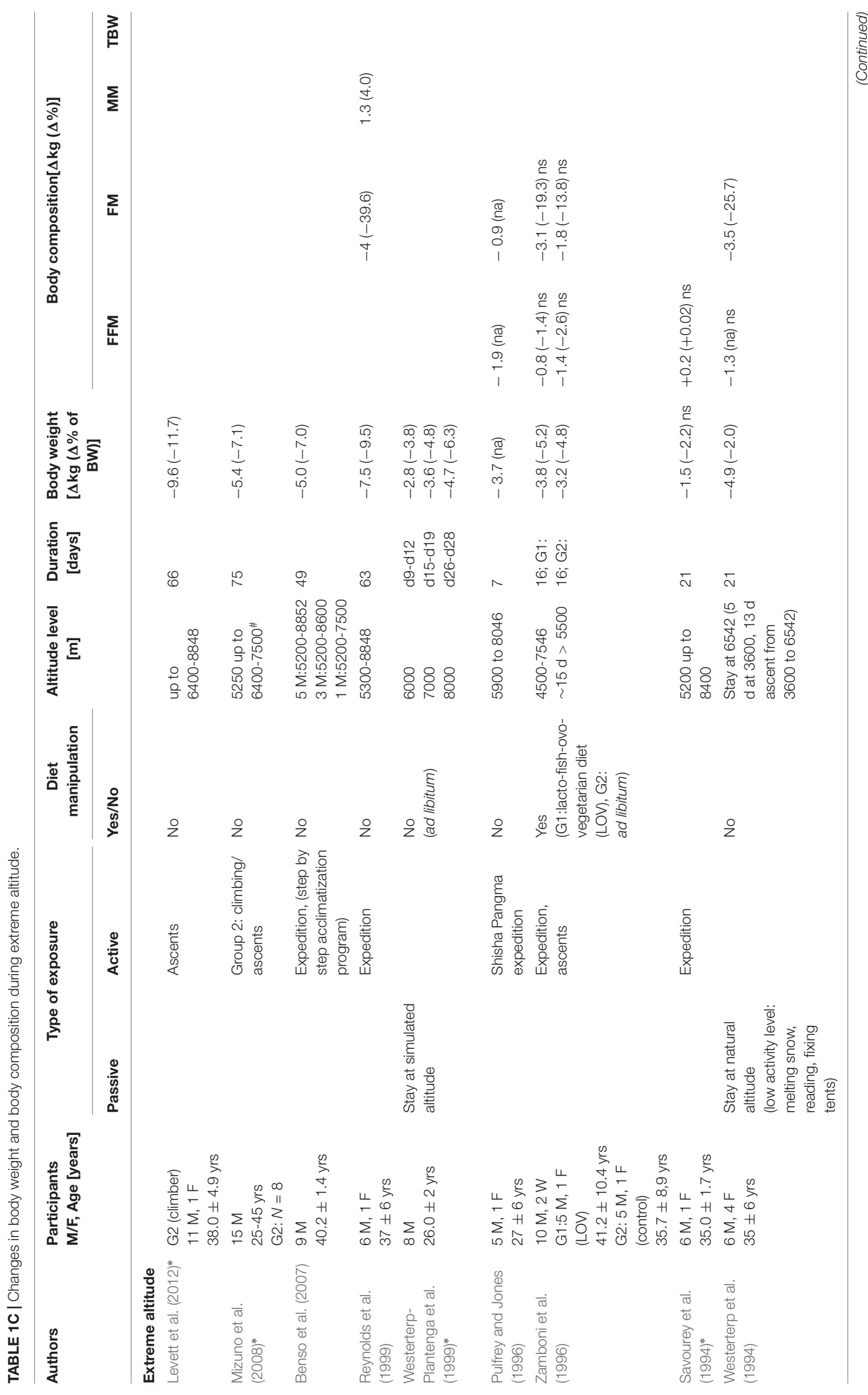




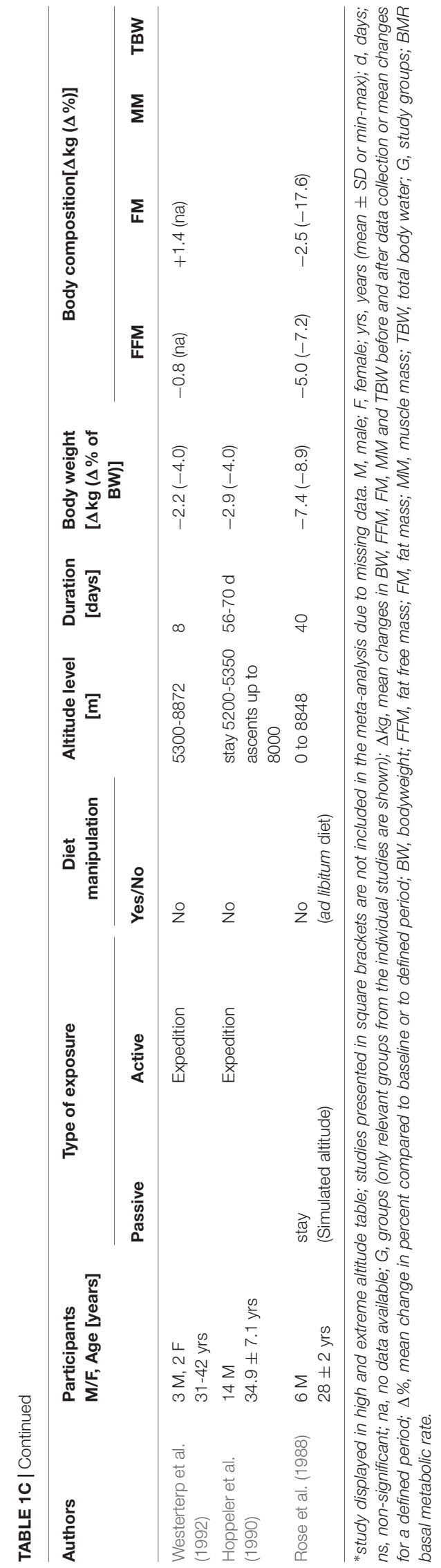

investigated in nine studies where reported losses ranged from -2.6 to $-0.1 \mathrm{~kg}$. The MM in the one study that involved passive exposure remained unchanged (ET: 7 days) (Lippl et al., 2010). A significant reduction in $\mathrm{MM}$ of $-1.5 \mathrm{~kg}$ was observed in male participants and an increase of $0.6 \mathrm{~kg}$ in female participants that had a prolonged active exposure to cold climate conditions (ET: 112 days) (Ocobock, 2017).

\section{High Altitude}

Physical activity was performed during 27 of the high altitude studies, whereas 14 studies employed passive hypoxic exposures only (Table 1B). In three studies, the effects of both passive and active hypoxia were investigated (Bharadwaj and Malhotra, 1974; Debevec et al., 2014a,b). Active exposures consisted primarily of trekking or mountaineering activity with only occasional cardiovascular-based endurance exercise of low- to moderateintensity. Fifteen studies manipulated food intake (Table 1B), two of which applied a hypocaloric diet (Fulco et al., 2002; Berryman et al., 2017). The duration of altitude (or simulated altitude) exposure varied from 4 days to 16 weeks (Table 1B). The mean age of subjects ranged from 21 to 56 years and $82 \%$ were male. The number of subjects ranged from 4 to 65 . Forty-one studies investigated changes in BW, 14 in FFM, 14 in FM and one study showed changes in MM.

Body weight reductions were recorded in 38 of the 41 studies, with individual weight loss ranging from -7.7 to $-0.01 \mathrm{~kg}$ over an ET of 4 to 75 days. Loss in body weight was more pronounced in studies that included active exposure $(-7.7$ to $-0.01 \mathrm{~kg})$ as compared to passive stays $(-4.9$ to $-0.4 \mathrm{~kg})$. A significant decrease in body weight was observed in 14 of the 15 studies with dietary manipulation. Body weight reduction ranged from -7.7 to $-0.01 \mathrm{~kg}$ in studies where energy intake was not manipulated, and from -7.2 to $-6.6 \mathrm{~kg}$ where a hypocaloric diet was applied (Fulco et al., 2002; Berryman et al., 2017). Body weight decreased by -3.1 to $-0.4 \mathrm{~kg}$ in studies where dietary supplements were given (Schena et al., 1992; Vats et al., 2007; Wing-Gaia et al., 2014) as well as studies with matched food intake (Holm et al., 2010; Debevec et al., 2014a,b) and increased energy intake (Surks et al., 1966; Consolazio et al., 1972; Bharadwaj and Malhotra, 1974; Butterfield et al., 1992; Mawson et al., 2000; Barnholt et al., 2006). Of the 14 studies evaluating FFM, 13 reported a decrease $(-4.6$ to $-0.1 \mathrm{~kg})$, and one recorded a slight increase of $0.5 \mathrm{~kg}$. Reductions in FFM varied between -3.9 to $-0.2 \mathrm{~kg}$ and -2.1 to $-0.1 \mathrm{~kg}$ in studies with active and passive exposures, respectively. FFM decreased by -2.4 to $-0.4 \mathrm{~kg}$ when dietary intake was not manipulated ( $N=5$; including changes from control groups of dietary manipulated studies), and by -2.1 to $-0.1 \mathrm{~kg}$ when intake was manipulated $(N=7)$ with the largest decreases $(-4.6$ to $-3.3 \mathrm{~kg}$ ) recorded in studies involving a hypocaloric diet (Fulco et al., 2002; Berryman et al., 2017).

Reductions in FM were reported in 12 of the 14 studies with -3.9 to $-0.2 \mathrm{~kg}$ in studies were exercise was performed and -1.7 to $-0.2 \mathrm{~kg}$ in studies with passive exposure. FM changed by -3.5 to $+0.6 \mathrm{~kg}$ in studies where nutritional intake was not manipulated, and by -1.7 to $0.5 \mathrm{~kg}$ in studies with nutritional manitpulation. 


\section{Extreme Altitude}

Physical activity was an inherent part of most of the extreme altitude studies (9 out of 12) (Table 1C). Three studies comprised passive exposures (Rose et al., 1988; Westerterp et al., 1994; Westerterp-Plantenga et al., 1999), two were performed in a hypobaric chamber (Rose et al., 1988; Westerterp-Plantenga et al., 1999) and one included a passive stay at real altitude (Westerterp et al., 1994). Active exposure consisted primarily of trekking, mountaineering and climbing. Energy intake was manipulated in one study that provided a lacto-fish-ovo-vegetarian diet (Zamboni et al., 1996). The mean age of the subjects ranged from 23 to 41 years. The number of subjects ranged from 5 to 14 , and $88 \%$ were male. The duration of altitude (or simulated altitude) exposure varied from 7 days to 10 weeks (Table 1C).

Body weight decreases were reported in all 12 studies with individual reductions between $-9.6 \mathrm{~kg}$ and $-1.5 \mathrm{~kg}$. Reductions in body weight were higher in the active studies $(-9.6$ to $-1.5 \mathrm{~kg}$ ) when compared to studies with passive exposures $(-7.4$ to $-2.7 \mathrm{~kg})$.

Individual FFM varied by -1.9 to $+0.2 \mathrm{~kg}$. A decrease of $-5.0 \mathrm{~kg}$ was reported in one study with passive hypobaric exposure at an altitude of up to $8848 \mathrm{~m}$ for 40 days (Rose et al., 1988). Individual FM losses ranged from -4.0 to $-0.9 \mathrm{~kg}$ and from -3.5 to $-2.5 \mathrm{~kg}$ in studies of active and passive exposure, respectively. MM was evaluated in one study and was shown to increase by $1.3 \mathrm{~kg}$ (ET: 63 days) (Reynolds et al., 1999).

\section{META-ANALYSIS}

The results of meta-analysis of all studies and for the subgroups: moderate, high and extreme altitudes, including mean changes in BW, FFM, FM, and MM are presented in Table 2. In addition, results are shown as forest plots in Figures 3-5. A pooled mean reduction in BW, FFM, FM, and MM was observed when all studies were analyzed together (Table 2) and in each subgroup (Table 2 and Figures 3-5). A random effects model was considered as the main method for meta-analysis and metaregression in order to account for the heterogeneity between studies. Meta-analysis of MM for the subgroup analysis was not possible due to an insufficient number of studies (only one study shown in two subgroups). Similarly, multivariate metaregression analysis was not possible for FFM and FM for studies performed at high altitude and extreme altitude, respectively. In addition, the low number of observations in studies at high and extreme altitude did not allow univariate and multivariate metaregression-analysis for FFM and MM. Subgroup analysis for the variables: diet, duration and type of exposure (active/passive) are presented in Table 3.

For studies conducted at moderate altitude, our meta-analysis reveals a statistically significant pooled mean reduction in BW of $1.7 \mathrm{~kg}(95 \% \mathrm{CI}-2.0$ to -1.3$)$. A pooled mean change in FFM indicates a reduction of $0.33 \mathrm{~kg}(95 \% \mathrm{CI}-0.9$ to -0.21$)$, and FM significantly decreases by, on average, $-0.33 \mathrm{~kg}(95 \%$ $\mathrm{CI}-0.9$ to 0.21$)$. The largest reductions in $\mathrm{BW}$ were observed when exposure was active $(-1.75 \mathrm{~kg}, 95 \% \mathrm{CI}-2.19$ to -1.30$)$, diet not manipulated $(-1.76 \mathrm{~kg}, 95 \% \mathrm{CI}-2.21$ to -1.30$)$
TABLE 2 | Random-effects meta-analysis results.

\begin{tabular}{|c|c|c|c|c|}
\hline Outcome & PMC [kg] & $95 \% \mathrm{Cl}$ & $N$ & $I^{2}$ \\
\hline \multicolumn{5}{|l|}{ BW } \\
\hline Overall & -2.6 & $(-3.1,-2.1)$ & 61 & $96 \%$ \\
\hline Moderate & -1.7 & $(-2.0,-1.3)$ & 13 & $43 \%$ \\
\hline High & -2.3 & $(-3.0,-1.6)$ & 38 & $97 \%$ \\
\hline Extreme & -4.9 & $(-6.2,-3.7)$ & 11 & $79 \%$ \\
\hline \multicolumn{5}{|l|}{ FFM } \\
\hline Overall & -1.3 & $(-1.8,-0.8)$ & 27 & $93 \%$ \\
\hline Moderate & -0.33 & $(-0.9,0.2)$ & 7 & $59 \%$ \\
\hline High & -1.5 & $(-1.0,-5.5)$ & 14 & $75 \%$ \\
\hline Extreme & -1.8 & $(-3.8,+17)$ & 6 & $93 \%$ \\
\hline \multicolumn{5}{|l|}{ FM } \\
\hline Overall & -1.5 & $(-2.0,-1.1)$ & 31 & $94 \%$ \\
\hline Moderate & -1.4 & $(-1.7,-1.1)$ & 12 & $60 \%$ \\
\hline High & -1.3 & $(-2.4,-0.2)$ & 13 & $97 \%$ \\
\hline Extreme & -2.7 & $(-4.2,-1.1)$ & 6 & $91 \%$ \\
\hline \multicolumn{5}{|l|}{ MM } \\
\hline Overall & -0.3 & $(-0.9,+0.4)$ & 6 & $76 \%$ \\
\hline
\end{tabular}

PMC, pooled mean change (95\% confidence interval); N, number of observations; overall, meta-analysis results including all studies; BW, body weight; FFM, fat free mass; FM, fat mass; MM, muscle mass; moderate altitude (1500-3500 m), high altitude $(3500-5300 \mathrm{~m})$, extreme altitude $(>5300 \mathrm{~m}) ; \mathrm{l}$, I-squared percentage of variation across studies due to heterogeneity; No results were observed for MM in subgroups moderate, high and extreme altitude due to insufficient number of observations.

and when duration was more than 42 days $(-2.30 \mathrm{~kg}, 95 \%$ CI -3.04 to -1.56$)$.

Results of the meta-analysis of studies at high altitude yields a significant pooled mean change in BW $(-2.3 \mathrm{~kg}, 95 \% \mathrm{CI}$ -3.0 to -1.6$)$, FFM $(-1.5 \mathrm{~kg}, 95 \% \mathrm{CI}-1.0$ to -5.5$)$ and FM $(-1.3 \mathrm{~kg}, 95 \% \mathrm{CI}-2.4$ to -0.2$)$. Pooled mean changes in BW are most pronounced in studies that involved active exposures $(-2.48 \mathrm{~kg}, 95 \% \mathrm{CI}-3.47$ to -1.48$)$, when diet was not manipulated $(-2.36 \mathrm{~kg}, 95 \% \mathrm{CI}-3.46$ to -1.26$)$ or hypocaloric $(-6.85 \mathrm{~kg}, 95 \% \mathrm{CI}-8.99$ to -4.72$)$ and when duration of the exposure ranged between 22 to 42 days $(-7.05 \mathrm{~kg}, 95 \% \mathrm{CI}$ -7.73 to -6.37$)$.

For studies conducted at extreme altitudes, there is a significant pooled mean change for BW $(-4.9 \mathrm{~kg}, 95 \% \mathrm{CI}$ -6.2 to -3.7$)$, FFM $(-1.8 \mathrm{~kg}, 95 \% \mathrm{CI}-3.8$ to +1.7$)$ and FM $(-2.7 \mathrm{~kg}, 95 \% \mathrm{CI}-4.2$ to -1.1$)$. Reductions in $\mathrm{BW}$ are similar in active $(-4.87 \mathrm{~kg}, 95 \% \mathrm{CI}-6.59$ to -3.16$)$ and passive exposures ( $-5.04 \mathrm{~kg}, 95 \% \mathrm{CI}-7.39$ to -2.70$)$, when diet was not manipulated $(-4.99 \mathrm{~kg}, 95 \% \mathrm{CI}-6.32$ to -3.65$)$ and when duration lasted between 22 and 42 days $(-7.40 \mathrm{~kg}, 95 \% \mathrm{CI}$ -9.16 to -5.64$)$.

\section{HETEROGENEITY}

Results of the analyses show a substantial and significant heterogeneity $\left(I^{2}\right)$ between studies, apropos BW, FFM, FM and $\mathrm{MM}$ at all altitude levels, and in subgroup analysis for moderate, high and extreme altitudes, with changes in BW, FFM, and FM ranging from 43 to $97 \%(p \leq 0.05)$. 


\section{A}

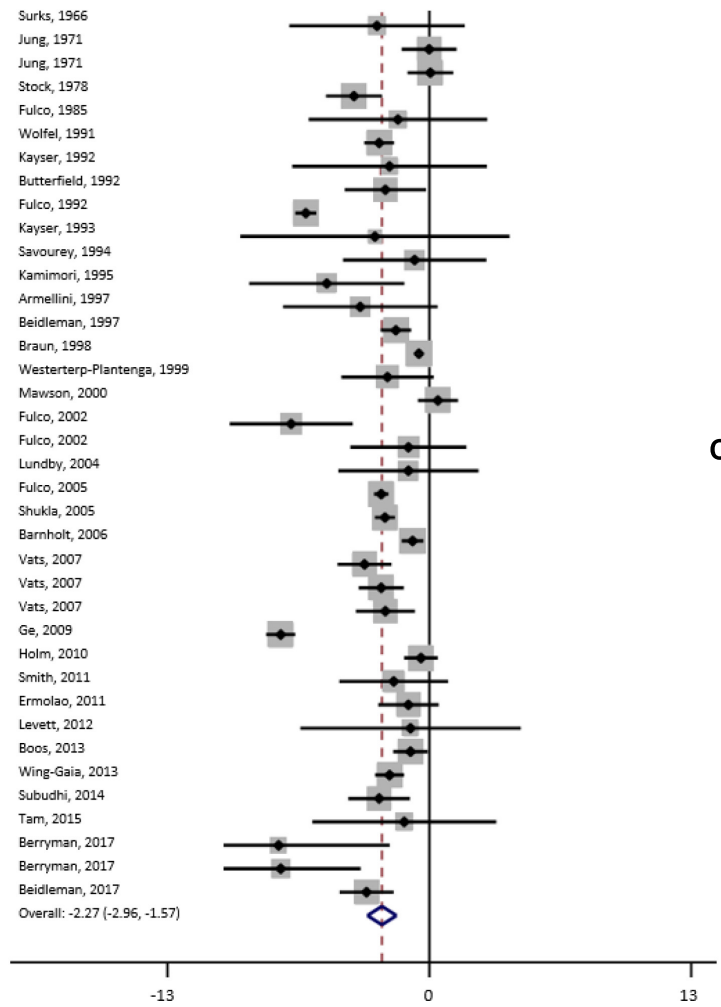

B

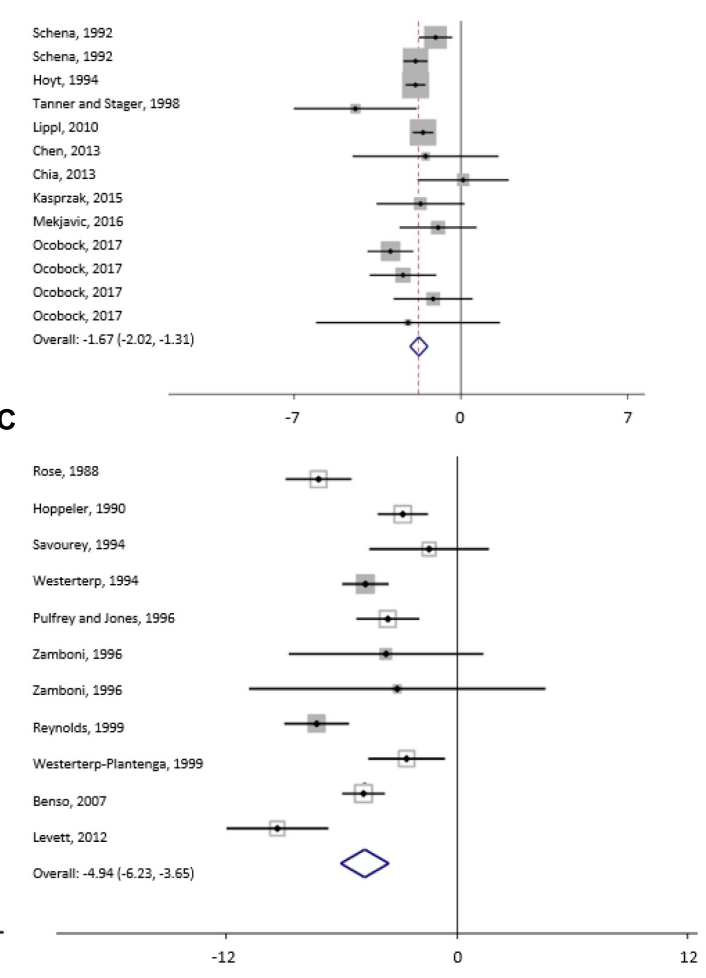

FIGURE 3 | Forest plot from random-effects meta-analysis of mean bodyweight changes (95\% Cl) in the subgroup high (A), moderate (B) and extreme (C) altitude.

The effects of available covariates on between-study heterogeneity for the outcomes "BW changes" and "body compositional changes" are first derived from univariate meta-regression. Thereafter, those covariates with a statistical significance level of $p<0.25$ are included in the multivariate meta-regression analysis for BW, FFM, and FM. Meta-regression results across all altitude levels are presented in Table 4. Results for changes in BW, FFM, and FM for studies at high- and extreme altitude subgroups are presented in Table 5.

\section{All Studies}

Univariate meta-regression results show that when compared to non-manipulation of diet, manipulation of diet and a hypocaloric diet explains $20 \%$, altitude (per $1000 \mathrm{~m}$ ) $40 \%$, altitude level (high/extreme versus moderate altitude) 30\%, duration of exposure $8 \%$, baseline bodyweight $2 \%$ and sex of subjects $8 \%$ of the total heterogeneity in BW changes between studies. Analyzing the significant covariates (manipulation of diet and hypocaloric diet, altitude level, duration and sex) in a multivariate metaregression, the model explains $49 \%$ of the between study variance in the changes in $\mathrm{BW}$.

For FFM, covariate manipulation of diet and hypocaloric diet explains $23 \%$ when compared to non-manipulation of diet, altitude level (high/extreme versus moderate altitude) $13 \%$, duration of exposure $17 \%$, baseline bodyweight $71 \%$ and sex $14 \%$ of the total heterogeneity between studies in a univariate meta-regression. Multivariate meta-regression, including significant covariates, reveals that manipulation of diet and addition of a hypocaloric diet together with altitude level (high/extreme versus moderate altitude) and sex explains $45 \%$ of the variance in changes of FFM between studies.

For FM, univariate regression shows that manipulation of diet and hypocaloric diet explains $8 \%$ when compared to non-manipulation of diet, altitude level (high/extreme versus moderate altitude) $12 \%$ and duration $42 \%$ of the heterogeneity. According to multivariate meta-regression, the model including significant covariates (altitude level and sex) explains $8 \%$ of the variance in the changes of FM between studies.

\section{Moderate Altitude}

None of the selected covariates explains any of the heterogeneity between studies in BW, FFM or FM changes for the subgroup "moderate altitude."

\section{High Altitude}

The results of the univariate meta-regression show that manipulation of diet and hypocaloric diet explains $21 \%$, duration of the exposure 20\%, sex of the subjects $13 \%$ and baseline bodyweight $0.4 \%$ of the heterogeneity in BW changes. When significant covariates are evaluated with multivariate regression, the model including manipulation of diet or hypocaloric diet and 


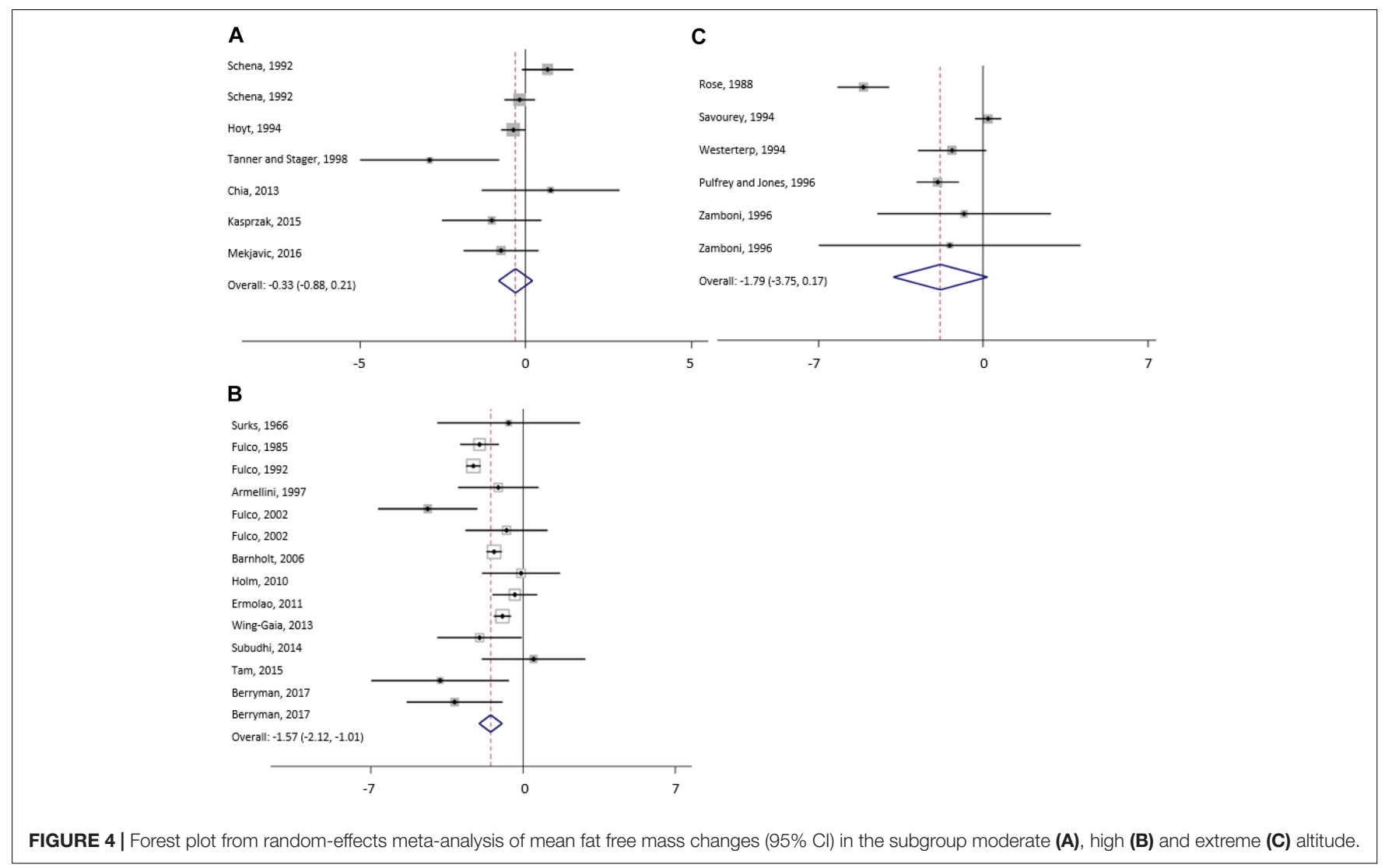

duration of exposure explains 35\% of the heterogeneity in BW changes between studies.

For FFM, most of the heterogeneity can be explained by manipulation of diet or hypocaloric diet (42\%) and sex of the subjects $(66 \%)$ when analyzed with univariate regression. Univariate regression reveals that manipulation of diet or hypocaloric diet explains $25 \%$ and type of exposure $30 \%$ of the heterogeneity in the changes of FM between studies. Results of the multivariate analysis show that significant covariates "sex" and "type of exposure" explain $42 \%$ of the heterogeneity.

\section{Extreme Altitude}

With respect to BW changes at extreme altitude, univariate regression shows that baseline bodyweight explains $84 \%$ of the heterogeneity whereas duration of exposure explains $14 \%$ (nonsignificant). Multivariate meta-regression results reveal that $84 \%$ of heterogeneity can be explained by duration of exposure, baseline bodyweight and altitude (per $1000 \mathrm{~m}$ ). In studies reporting FM, most of the heterogeneity can be explained by the age of the participants (77\%) and by the duration of the exposure $(42 \%)$ when analyzed with univariate meta-regression.

\section{Publication Bias}

Beggs's funnel plots displayed a clear asymmetry for BW (Figure 6A) and a slight asymmetry for FM (Figure 6B) indicating a lack of publications for smaller studies reporting increases in BW or FM. No significant asymmetry was found for FFM. Results from Eggers test indicate a publication bias in all studies for reports of BW changes $(p \leq 0.001$, $N=62$ ) whereas no evidence for publication bias was shown for FFM, FM and MM.

\section{DISCUSSION}

In summary, the results of the present meta-analysis show a decrease in pooled mean BW in the subgroups: moderate, high and extreme altitude, and where described, are accompanied by pooled mean decreases in body composition (i.e., FFM, FM), with larger changes occurring at higher altitudes. The between study heterogeneity can be explained, at least in part, by the duration of the altitude stay, the level of physical activity and nutrition.

At moderate altitude, none of the selected covariates (age, sex, baseline bodyweight, diet, active or passive exposure, duration) can explain the between study heterogeneity in BW, FFM or FM. Nonetheless, pooled mean decreases in BW are most pronounced when participants are active and when the duration of the exposure exceeds 42 days. Interestingly, at moderate altitude, clinically relevant reductions in BW of obese participants reported in the one controlled study (Greie et al., 2006) were similar to those in the normoxic control group. Only marginal reductions in FM were observed by Lippl et al. (2010) and Mekjavic et al. (2016) after 7 and 10 days of passive exposure, respectively, whereas significant reductions in FM were reported in studies that involved physical activity. Thus, the results of 


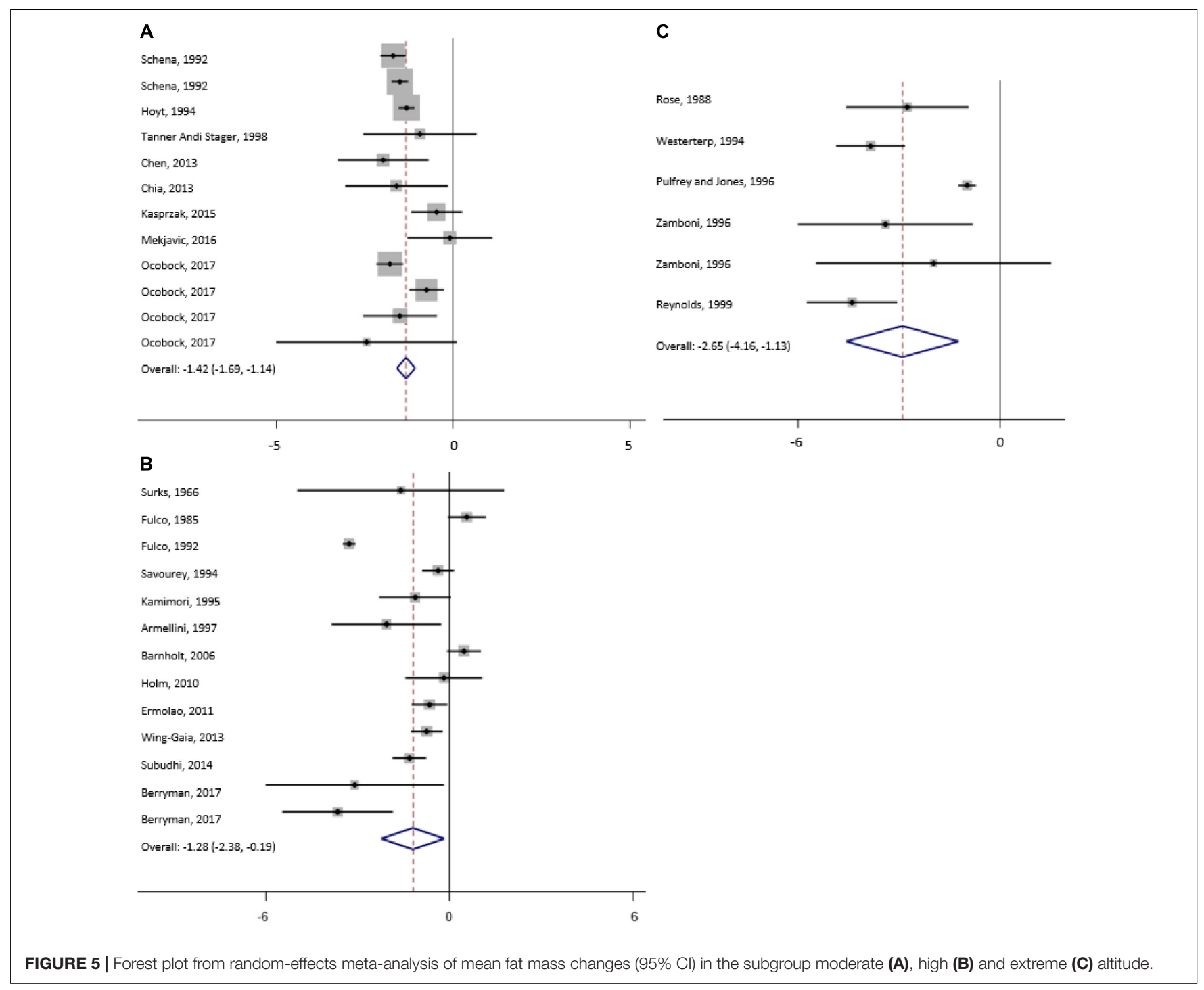

the studies performed at moderate altitude are not consistent in regard to the effect of hypoxia on BW or FM reduction.

At high altitude, diet (21\%) and duration (20\%) explains most of the heterogeneity in BW changes between studies. Sex and diet explains 66 and $42 \%$ of the between study heterogeneity in FFM changes, respectively, whereas diet and type of exposure (active/passive) explains 25 and 30\% of between study heterogeneity in changes in FM, respectively. At high altitude, as at moderate altitude, the pooled mean decreases in BW were higher with active exposure and when diet was not manipulated or when the diet was hypocaloric. However, even when the caloric intake was matched or increased relative to output, BW still significantly decreased by -2.5 to $-0.4 \mathrm{~kg}$, indicating hypoxia to be a possible trigger for body composition changes in these studies (Surks et al., 1966; Consolazio et al., 1972; Bharadwaj and Malhotra, 1974; Wolfel et al., 1991; Butterfield et al., 1992; Barnholt et al., 2006; Holm et al., 2010). Studies that revealed the highest pooled mean reductions in BW at high altitude were those with durations of 22 to
42 days. In these studies, on average, FFM and FM affected the pooled mean body weight changes to a similar extent. There was one study of patients of type 2 diabetes mellitus that reported no changes in body weight after a 12 -week expedition (De Mol et al., 2012).

At extreme altitude, a baseline BW accounts for most of the heterogeneity in BW changes between studies (84\%) whereas the duration of exposure accounts for $14 \%$. In addition, heterogeneity in FM changes between studies can be explained by the age of subjects $(77 \%)$. The pooled mean decreases in BW in studies performed at extreme altitude were quite similar when physical activity was implemented or not, when diet was not manipulated and when duration lasted from 22 to 42 days. Data on MM was only reported for one study, where MM actually increased (Reynolds et al., 1999).

Reductions in BW and changes in body composition are commonly observed in high altitude research. The mechanisms leading to these changes are varied and include, but are not limited to, a higher resting metabolic rate, loss of appetite and 
TABLE 3 | Subgroup analyses for exposure, diet, exposure and duration.

\begin{tabular}{|c|c|c|c|c|c|c|}
\hline & BW & $N$ & FFM & $N$ & FM & $N$ \\
\hline & PMC (95\% Cl) & & PMC (95\% Cl) & & PMC (95\% Cl) & \\
\hline \multicolumn{7}{|l|}{ Moderate altitude } \\
\hline \multicolumn{7}{|l|}{ Exposure } \\
\hline Active & $-1.75(-2.19,-1.30)$ & 11 & $-0.28(-0.89,0.33)$ & 6 & $-1.47(-1.73,-1.21)$ & 11 \\
\hline Passive & $-1.46(-1.86,-1.05)$ & 2 & $-0.80(-2.01,0.41)$ & 1 & $-0.10(-1.37,1.17)$ & 1 \\
\hline \multicolumn{7}{|l|}{ Diet } \\
\hline Manipulated & $-1.45(-2.23,-0.67)$ & 2 & $0.09(-0.98,1.16)$ & 2 & $-1.57(-1.96,-1.18)$ & 2 \\
\hline Non-manipulated & $-1.76(-2.21,-1.30)$ & 11 & $-0.71(-1.58,0.16)$ & 5 & $-1.32(-1.72,-0.91)$ & 10 \\
\hline Hypocaloric & n.a. & & n.a. & & n.a. & \\
\hline \multicolumn{7}{|l|}{ Duration [days] ${ }^{*}$} \\
\hline $0-7$ & $-1.66(1.95,-1.36)$ & 2 & & & & \\
\hline 8-14 & $-1.20(-2.36,-0.05)$ & 2 & & & & \\
\hline $15-21$ & $-1.48(-2.44,-0.50)$ & 4 & & & & \\
\hline $22-42$ & $-1.40(-4.31,1.51)$ & 1 & & & & \\
\hline$>42$ & $-2.30(-3.04,-1.56)$ & 4 & & & & \\
\hline \multicolumn{7}{|l|}{ High altitude } \\
\hline \multicolumn{7}{|l|}{ Exposure } \\
\hline Active & $-2.48(-3.47,-1.48)$ & 25 & $-1.71(-2.52,-0.90)$ & 10 & $-1.88(-3.13,-0.63)$ & 8 \\
\hline Passive & $-1.70(-2.38,-1.01)$ & 13 & $-1.45(-2.04,-0.86)$ & 4 & $0.05(-0.62,0.73)$ & 5 \\
\hline \multicolumn{7}{|l|}{ Diet } \\
\hline Manipulated & $-1.40(-2.06,-0.74)$ & 12 & $-1.19(-1.46,-0.92)$ & 5 & $-0.25(-1.15,0.65)$ & 4 \\
\hline Non-manipulated & $-2.36(-3.46,-1.26)$ & 23 & $-1.51(-2.39,-0.64)$ & 6 & $-1.24(-2.70,0.22)$ & 7 \\
\hline hypocaloric & $-6.85(-8.99,-4.72)$ & 3 & $-3.94(-5.43,-2.46)$ & 3 & $-3.73(-5.37,-2.10)$ & 2 \\
\hline \multicolumn{7}{|l|}{ Duration [days] ${ }^{*}$} \\
\hline $0-7$ & $-0.37(-1.10,0.36)$ & 5 & & & & \\
\hline $8-14$ & $-1.62(-2.30,-0.92)$ & 13 & & & & \\
\hline $15-21$ & $-2.68(-3.99,-1.37)$ & 15 & & & & \\
\hline $22-42$ & $-7.05(-7.73,-6.37)$ & 4 & & & & \\
\hline$>42$ & $-1.00(-4.35,2.35)$ & 1 & & & & \\
\hline \multicolumn{7}{|l|}{ Extreme altitude } \\
\hline \multicolumn{7}{|l|}{ Exposure } \\
\hline Active & $4.87(-6.59,-3.16)$ & 8 & $-0.86(-2.50,0.79)$ & 4 & $-2.43(-4.47,-0.39)$ & 4 \\
\hline Passive & $-5.04(-7.39,-2.70)$ & 3 & $-3.18(-6.81,0.45)$ & 2 & $-3.25(-4.09,-2.40)$ & 2 \\
\hline \multicolumn{7}{|l|}{ Diet } \\
\hline Manipulated & $-3.80(-8.99,1.39)$ & 1 & $-0.80(-4.42,2.82)$ & 1 & $-3.10(-5.46,-0.74)$ & 1 \\
\hline Non-manipulated & $-4.99(-6.32,-3.65)$ & 10 & $-1.93(-4.06,0.21)$ & 5 & $-2.57(-4.23,-0.91)$ & 5 \\
\hline hypocaloric & n.a. & & n.a. & & n.a. & \\
\hline \multicolumn{7}{|l|}{ duration [days]* } \\
\hline $0-7$ & $-3.70(-5.38,-2.02)$ & 1 & & & & \\
\hline $8-14$ & $-2.70(-4.75,-0.66)$ & 1 & & & & \\
\hline $15-21$ & $-3.92(-5.70,-2.14)$ & 4 & & & & \\
\hline $22-42$ & $-7.40(-9.16,-5.64)$ & 1 & & & & \\
\hline$>42$ & $-6.05(-8.49,-3.61)$ & 4 & & & & \\
\hline
\end{tabular}

PMC, pooled mean change (95\% confidence interval); N, number of observations; BW, body weight; FFM, fat free mass; FM, fat mass; moderate altitude (1500-3500 m), high altitude (3500-5300 m), extreme altitude (>5300 m); n.a., no data available; *insufficient number of observations for FFM and FM.

possible impaired intestinal function at higher altitudes (Matu et al., 2018). The limitation of most of the research on this topic is that, in addition to the hypoxia level, other factors such as nutrition and exercise may greatly contribute to the observed body compositional changes. This is of particular importance as most of the studies were observational in nature, and the duration and intensity of physical activity as well as the nutritional intake were not controlled. Thus, the magnitude of their influence is difficult to assess. Nonetheless, the greatest body mass losses occurred when heavy exercise or exercise over a long duration (trekking) was incorporated and when a hypocaloric diet was applied. In contrast, the magnitude of loss was seemingly less under resting conditions and in cases where food intake was matched to energy expenditure. Interestingly, in a recent review, the degree of hypoxia was positively related to the suppression of the hunger signaling hormone acylated ghrelin 
TABLE 4 | Explained between study heterogeneity $(\mathrm{EH})$ by selected variables from univariate and multivariate meta-regression across all altitude levels.

\begin{tabular}{|c|c|c|c|c|c|}
\hline Model & $N$ & PMC (in kg with 95\% Cl) & EH & $p$ value & Publication bias (Egger- Test) \\
\hline BW & & & & & $\leq 0.001$ \\
\hline \multicolumn{6}{|l|}{ Univariate } \\
\hline Manipulation of diet/ & 62 & $1.32(0.17,2.47)$ & $20 \%$ & 0.03 & \\
\hline hypocaloric diet & & $-4.10(-7.50,-1.44)$ & & 0.01 & \\
\hline Altitude (per 1000 m) & 62 & $-0.91(-1.31,-0.51)$ & $40 \%$ & $\leq 0.001$ & \\
\hline High altitude vs. moderate altitude & 62 & $-0.56(-1.73,-0.61)$ & $30 \%$ & 0.35 & \\
\hline Extreme altitude vs. moderate altitude & & $-3.26(-4.82,-1.70)$ & & $\leq 0.001$ & \\
\hline Duration (days) & 62 & $-0.03(-.458,-0.002)$ & $8 \%$ & 0.03 & \\
\hline Baseline bodyweight & 57 & $-0.07(-0.12,0.01)$ & $2 \%$ & 0.06 & \\
\hline Sex (male) & & $-0.02(-0.04,-0.002)$ & $8 \%$ & 0.03 & \\
\hline Multivariate & 62 & & $49 \%$ & & \\
\hline Manipulation of diet/ & & $0.62(-0.39,1.64)$ & & 0.22 & \\
\hline Hypocaloric diet & & $-4.12(-6.98,-1.27)$ & & $\leq 0.01$ & \\
\hline High altitude vs. moderate altitude & & $-1.05(-2.20,-0.10)$ & & 0.07 & \\
\hline Extreme altitude vs. moderate altitude & & $-3.06(-4.46,-1.66)$ & & $\leq 0.001$ & \\
\hline Duration (days) & & $-0.02(-0.04,-0.002)$ & & 0.03 & \\
\hline Sex (male) & & $-0.02(-0.03,-0.002)$ & & 0.02 & \\
\hline FFM & & & & & 0.73 \\
\hline \multicolumn{6}{|l|}{ Univariate } \\
\hline Manipulation of diet/ & 27 & $0.84(-0.37,2.04)$ & $23 \%$ & 0.16 & \\
\hline hypocaloric diet & & $-2.56(-4.75,-0.38)$ & & 0.02 & \\
\hline High altitude vs. moderate altitude & 27 & $-1.10(-2.46,-0.21)$ & $13 \%$ & 0.10 & \\
\hline Extreme altitude vs. moderate altitude & & $-1.35(-3.00,-0.29)$ & & 0.10 & \\
\hline Duration (days) & 27 & $-0.09(-0.17,-0.01)$ & $17 \%$ & 0.03 & \\
\hline Baseline bodyweight & 22 & $-0.12(-0.18,-0.07$ & $71 \%$ & $\leq 0.001$ & \\
\hline Sex (male) & 27 & $-0.02(-0.04,-0.0002)$ & $14 \%$ & 0.05 & \\
\hline Multivariate & 27 & & $45 \%$ & & \\
\hline Manipulation of diet/ & & $0.89(-0.25,2.02)$ & & 0.12 & \\
\hline hypocaloric diet & & $-1.81(-4.02,0.41)$ & & 0.10 & \\
\hline High altitude vs. moderate altitude & & $-1.13(-2.32,0.06)$ & & 0.06 & \\
\hline Extreme altitude vs. moderate altitude & & $-1.22(-2.65,0.21)$ & & 0.09 & \\
\hline Sex (male) & & $-0.02(-0.04,-0.003)$ & & 0.03 & \\
\hline FM & & & & & 0.48 \\
\hline \multicolumn{6}{|l|}{ Univariate } \\
\hline Manipulation of diet & 31 & $0.52(-0.56,1.60)$ & $8 \%$ & 0.34 & \\
\hline hypocaloric diet & & $-2.14(-4.55,0.26$ & & 0.08 & \\
\hline Altitude (per 1000 m) & 31 & $-0.27(-0.64,0.11)$ & $2 \%$ & 0.16 & \\
\hline High altitude vs. moderate altitude & 31 & $0.21(-0.75,1.18)$ & $12 \%$ & 0.65 & \\
\hline Extreme altitude vs. moderate altitude & & $-1.22(-2.50,-0.04)$ & & 0.06 & \\
\hline Duration (days) & & & $42 \%$ & & \\
\hline Multivariate & 31 & & $8 \%$ & & \\
\hline High altitude vs. moderate altitude & & $0.21(-0.78,1.19)$ & & 0.67 & \\
\hline Extreme altitude vs. moderate altitude & & $-1.23(-2.52,0.07)$ & & 0.06 & \\
\hline Sex (male) & & $0.002(-2.98,-0.11)$ & & 0.79 & \\
\hline
\end{tabular}

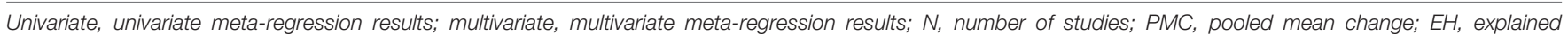

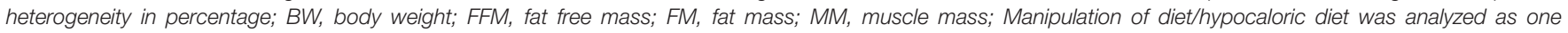

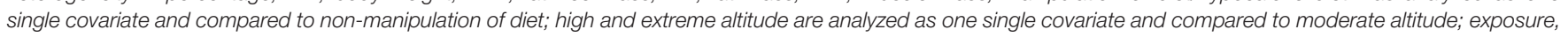
compared to passive exposure.

(Matu et al., 2018), confirming previous findings of reduced appetite due to a reduction of the acylated ghrelin concentration following high or extreme altitude exposure over less than moderate sojourns of several days (Matu et al., 2017). This might explain the absence of significant FM reductions in the studies by Lippl et al. (2010) and Mekjavic et al. (2016) with passive exposures to a moderate altitude.

Significant losses of FFM and MM were observed at altitudes as low as $\leq 5000 \mathrm{~m}$ (Ocobock, 2017), with the extent dependent on duration, temperature and body fat percentage at the outset. 


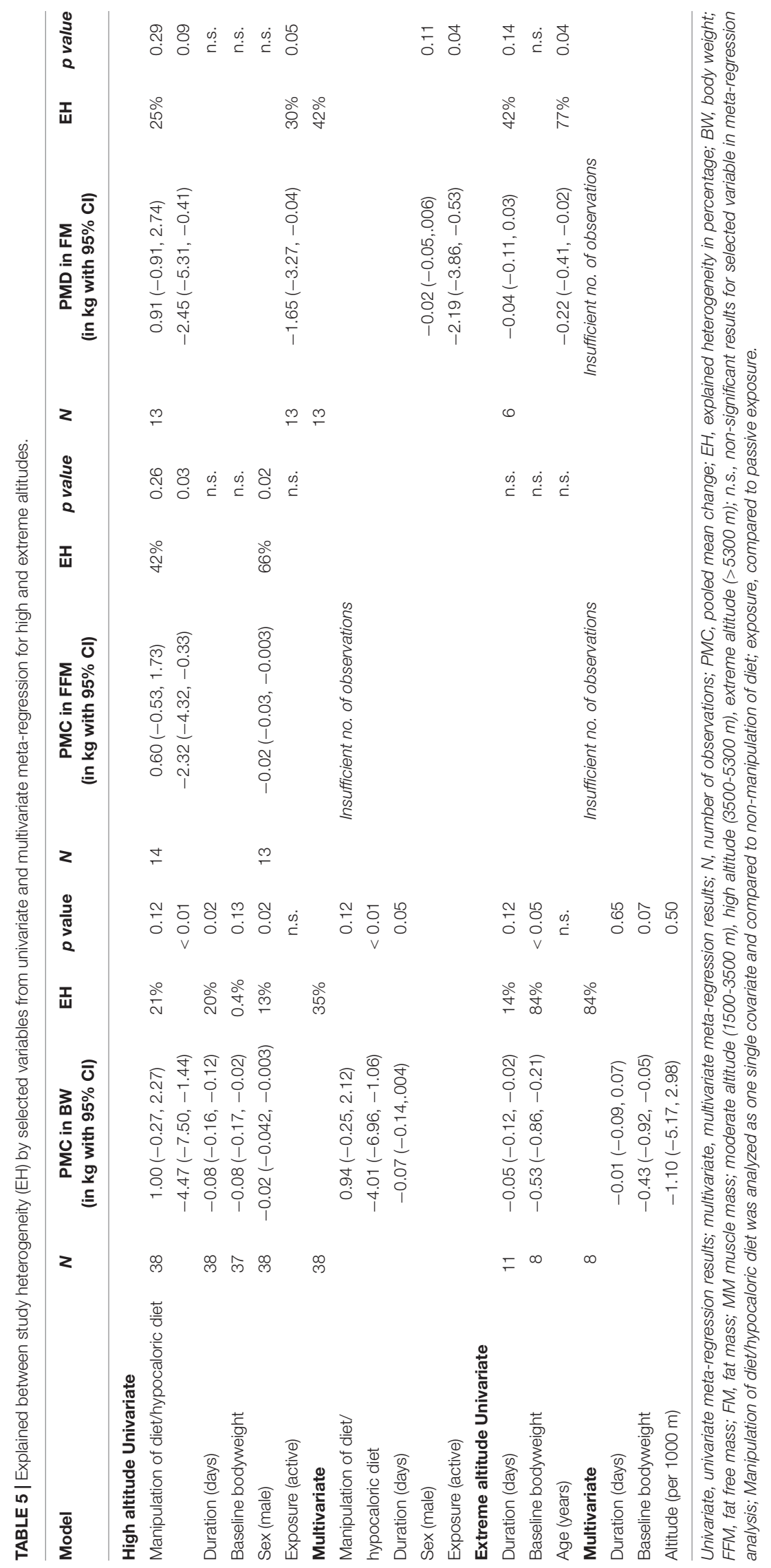



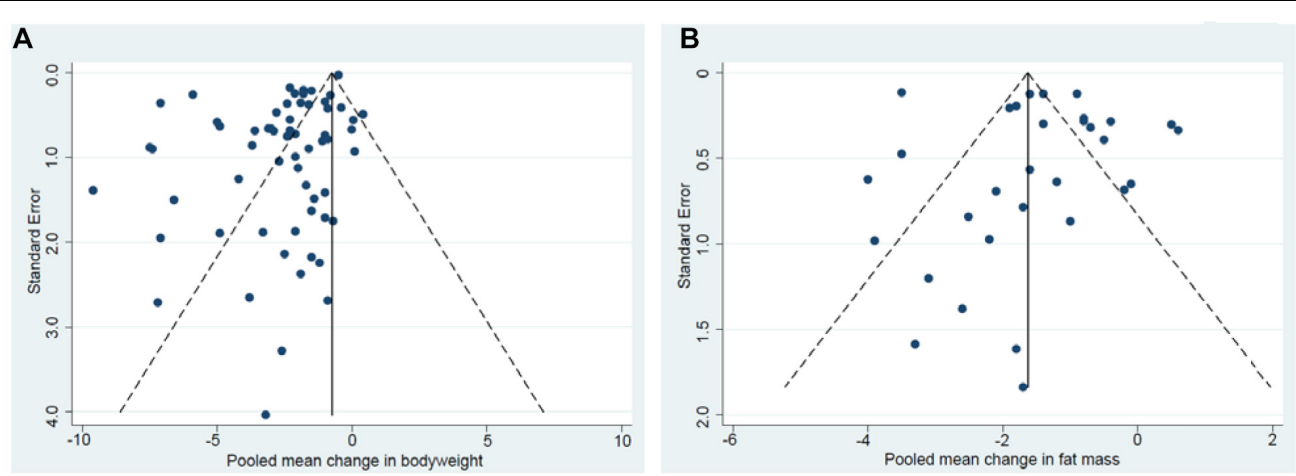

FIGURE 6 | Begg's funnel plot of changes in bodyweight (A). Begg's funnel plot of changes in fat mass (B).

These results were confirmed in a very recent study that showed that there is muscle wasting even during short simulated exposures (21 days) to an altitude of only $4000 \mathrm{~m}$ under strictly controlled and standardized environmental, dietary and activity conditions (Debevec et al., 2018). In the present review, only 5 studies reported data on TBW. Fluid loss equivalent to up to $1-2 \mathrm{~kg}$ of body weight is reported to accompany the adaptation to altitude (Kayser, 1994). Overall, maximum TBW loss was similar under moderate and high altitude conditions (approximately $-0.7 \mathrm{~L}(\mathrm{~ns})$ to $-1.1 \mathrm{~L}$ ), whereas no changes were reported at extreme altitudes. The fluid loss is suggested to be based on hormonally induced diuresis and natriuresis, decreased voluntary salt and water intake and increased insensible water loss (respiratory and surface water loss) (Hoyt and Honig, 1996), though exercise and/or hypertension may affect these processes (Ledderhos et al., 2002). As a consequence, plasma volume, interstitial and intracellular fluid volumes decrease, whereas hemoglobin concentration, mitochondrial- and capillary density increase, potentially resulting in increased skeletal muscle oxygen conductance and facilitated diffusion (Hoyt and Honig, 1996). Such changes might be beneficial for physical performance, however, detrimental effects due to excessive dehydration at altitude may occur.

One very important factor that one should not ignore when discussing body composition changes in lowlanders exposed to high altitudes is the general influence of genetic involvement in the adaptation to hypoxia. In high altitude natives, increased lung capacity (due to larger chests) was shown to be accompanied by increased diffusion capacity for oxygen (Greksa et al., 1994), which would imply a lesser degree of hyperventilation during hypoxia and, consequently, a lesser insensible water loss. In addition, metabolic factors such as fuel preference for carbohydrates at rest and during exercise may be involved in body composition adaptations in highlanders (Watt et al., 1976). Thus, changes in body composition may not only be based on an adaptive response to hypoxia but may also depend on different genetic factors.

\section{Practical and Clinical Implications}

It is not entirely clear whether the duration of the altitude stay or the severity of hypoxia is the more potent trigger in initiating weight loss. In regard to moderate altitude conditions, prolonged sojourns, especially if combined with hiking activities, may reduce BW and FM. However, these changes may not be induced by hypoxia alone since comparable hiking studies under normoxic conditions showed similar results. Moderate altitudes seem not to meaningfully decrease FFM and MM or affect appetite. When going to high altitude, climbers should consider that an increased BMR in conjunction with higher energy demands due to physical activity and inadequate energy intake - possibly due to loss of appetite - can lead to a negative energy balance resulting in loss of FM and FFM. Even during passive high and extreme altitude sojourns with matched or increased energy intake, changes in body composition, including reductions in FFM and FM, may occur. This emphasizes the importance of adequate nutritional intake, especially during active altitude exposure, to keep weight loss and, thus, FFM and MM reductions, which might negatively affect mountaineering performance and safety, to a minimum. Focus has to be also put on appropriate fluid intake as reduced fluid intake and increased fluid loss may lead to BW loss due to dehydration, which again may negatively affect performance and safety. Yet potential positive effects on performance, as outlined before, might also be anticipated. In addition it has to be mentioned that due to individual adaptation to hypoxia, the effects on body composition and BW may vary greatly between individuals exposed to high and extreme altitudes.

The observations of an increased energy expenditure, increased lipid metabolism and decreased glycogen metabolism following passive hypoxic conditioning (Workman and Basset, 2012) may lead to the assumption that, if applied with an adequate duration and severity, hypoxia could induce favorable weight loss in obese or overweight persons. The underlying mechanism leading to weight reduction during altitude sojourns is not entirely clear, and the effect of hypoxia per se remains unexplained. Fluid loss from all compartments (extra- and intracellular) as a response to hypoxic exposure might improve oxygen delivery due to reduced diffusion distances (Hoyt and Honig, 1996) and thus might facilitate a shift in fuel metabolism towards fat. The altitude specific effect (normobaric hypoxia) for potential weight loss programs in overweight persons was recently appraised by a systematic review (Hobbins et al., 2017). 
Some limitations of the review have to be acknowledged. Even though a systematic literature search was applied, there is the possibility that some relevant studies were not included in this meta-analysis if our search algorithm did not capture them. A significant publication bias was detected in all studies for BW changes. Additionally, and as already mentioned in the introduction section, it is not possible to unequivocally identify the influence of $\mathrm{AL}$ alone on body compositional changes due to the nature of most of the included studies (i.e., uncontrolled observational studies). Nevertheless, this analytical review gives a synopsis of the body compositional changes at various altitudes under different field conditions with a focus on the role of physical activity, duration of the exposure and nutrition.

In conclusion, BW and body composition changes occur during sojourns at different altitudes. The mechanisms leading to these changes are manifold and the magnitude of change is, in addition to the individual adaptive response to hypoxia,

\section{REFERENCES}

Armellini, F., Zamboni, M., Robbi, R., Todesco, T., Bissoli, L., Mino, A., et al. (1997). The effects of high altitude trekking on body composition and resting metabolic rate. Horm. Metab. Res. 29, 458-461. doi: 10.1055/s-2007-979077

Baggish, A. L., and Wolfel, E. E. (2014). "Cardiovascular system," in High Altitude: Human Adaptation to Hypoxia, 1 Edn, eds E. R. Swenson and P. Bärtsch (New York, NY: Springer), 103-139. doi: 10.1007/978-1-4614-8772-2_6

Barnholt, K. E., Hoffman, A. R., Rock, P. B., Muza, S. R., Fulco, C. S., Braun, B., et al. (2006). Endocrine responses to acute and chronic high-altitude exposure $(4,300$ meters): modulating effects of caloric restriction. Am. J. Physiol. Endocrinol. Metab. 290, E1078-E1088. doi: 10.1152/ajpendo.00449.2005

Beidleman, B. A., Fulco, C. S., Cadarette, B. S., Cymerman, A., Buller, M. J., Salgado, R. M., et al. (2017). Is normobaric hypoxia an effective treatment for sustaining previously acquired altitude acclimatization? J. Appl. Physiol. 123, 1214-1227. doi: 10.1152/japplphysiol.00344.2017

Beidleman, B. A., Muza, S. R., Rock, P. B., Fulco, C. S., Lyons, T. P., Hoyt, R. W., et al. (1997). Exercise responses after altitude acclimatization are retained during reintroduction to altitude. Med. Sci. Sports Exerc. 29, 1588-1595. doi: 10.1097/00005768-199712000-00007

Benso, A., Broglio, F., Aimaretti, G., Lucatello, B., Lanfranco, F., Ghigo, E., et al. (2007). Endocrine and metabolic responses to extreme altitude and physical exercise in climbers. Eur. J. Endocrinol. 157, 733-740. doi: 10.1530/EJE-07-0355

Berryman, C. E., Young, A. J., Karl, J. P., Kenefick, R. W., Margolis, L. M., Cole, R. E., et al. (2017). Severe negative energy balance during $21 \mathrm{~d}$ at high altitude decreases fat-free mass regardless of dietary protein intake: a randomized controlled trial. FASEB J. 32, 894-905. doi: 10.1096/fj.201700915R

Bharadwaj, H., and Malhotra, M. S. (1974). Body composition changes after 4 week acclimatization to high altitude: anthropometric and roentgenogrammetric evaluation. Z. Morphol. Anthropol. 65, 285-292.

Boos, C. J., Holdsworth, D. A., Hall, D. P., Mellor, A., O'hara, J., and Woods, D. R. (2014). Comparison of two methods of assessing total body water at sea level and increasing high altitude. Clin. Physiol. Funct. Imaging 34, 478-484. doi: $10.1111 /$ cpf.12121

Bradwell, A. R., Dykes, P. W., Coote, J. H., Forster, P. J., Milles, J. J., Chesner, I., et al. (1986). Effect of acetazolamide on exercise performance and muscle mass at high altitude. Lancet 1, 1001-1005. doi: 10.1016/S0140-6736(86)91272-9

Braun, B., Butterfield, G. E., Dominick, S. B., Zamudio, S., Mccullough, R. G., Rock, P. B., et al. (1998). Women at altitude: changes in carbohydrate metabolism at 4,300-m elevation and across the menstrual cycle. J. Appl. Physiol. 85, 1966-1973. doi: 10.1152/jappl.1998.85.5.1966

Brooks, G. A. (2014). "Nutrition and metabolism," in High Altitude: Human Adaptation to Hypoxia, 1 Edn, eds E. R. Swenson and P. Bärtsch (New York, NY: Springer), 285-323. doi: 10.1007/978-1-4614-8772-2_15 greatly influenced by the $\mathrm{AL}$, the duration of the stay, the level of physical activity and the nutritional intake. This review identifies at least two contrasting motivations for hypoxia exposure; the experience of high altitude mountaineering and the "therapeutic" effect of hypoxia (e.g., weight loss programs). This analytical review of published data highlights the notion that adequate nutritional intake during high altitude expeditions should be assured in order to prevent negative energy balance. Furthermore, there is currently no convincing evidence for the use of hypoxic treatments for obesity that do not involve any lifestyle modification and, as such, presents a focus for further investigations.

\section{AUTHOR CONTRIBUTIONS}

All authors listed have made a substantial, direct and intellectual contribution to the work, and approved it for publication.

Burtscher, M., Gatterer, H., Burtscher, J., and Mairbaurl, H. (2018). Extreme terrestrial environments: life in thermal stress and hypoxia. A narrative review. Front. Physiol. 9:572. doi: 10.3389/fphys.2018.00572

Butterfield, G. E., Gates, J., Fleming, S., Brooks, G. A., Sutton, J. R., and Reeves, J. T. (1992). Increased energy intake minimizes weight loss in men at high altitude. J. Appl. Physiol. 72, 1741-1748. doi: 10.1152/jappl.1992.72.5.1741

Chen, M. T., Lee, W. C., Chen, S. C., Chen, C. C., Chen, C. Y., Lee, S. D., et al. (2010). Effect of a prolonged altitude expedition on glucose tolerance and abdominal fatness. Res. Q. Exerc. Sport 81, 472-477. doi: 10.1080/02701367. 2010.10599708

Chia, M., Liao, C. A., Huang, C. Y., Lee, W. C., Hou, C. W., Yu, S. H., et al. (2013). Reducing body fat with altitude hypoxia training in swimmers: role of blood perfusion to skeletal muscles. Chin. J. Physiol. 56, 18-25. doi: 10.4077/CJP.2013. BAA071

Consolazio, C. F., Johnson, H. L., Krzywicki, H. J., and Daws, T. A. (1972). Metabolic aspects of acute altitude exposure (4,300 meters) in adequately nourished humans. Am. J. Clin. Nutr. 25, 23-29. doi: 10.1093/ajcn/25.1.23

De Mol, P., Fokkert, M. J., De Vries, S. T., De Koning, E. J., Dikkeschei, B. D., Gans, R. O., et al. (2012). Metabolic effects of high altitude trekking in patients with type 2 diabetes. Diabetes Care 35, 2018-2020. doi: 10.2337/dc12-0204

Debevec, T., Bali, T. C., Simpson, E. J., Macdonald, I. A., Eiken, O., and Mekjavic, I. B. (2014a). Separate and combined effects of 21-day bed rest and hypoxic confinement on body composition. Eur. J. Appl. Physiol. 114, 2411-2425. doi: 10.1007/s00421-014-2963-1

Debevec, T., Mcdonnell, A. C., Macdonald, I. A., Eiken, O., and Mekjavic, I. B. (2014b). Whole body and regional body composition changes following 10-day hypoxic confinement and unloading-inactivity. Appl. Physiol. Nutr. Metab. 39, 386-395. doi: 10.1139/apnm-2013-0278

Debevec, T., Ganse, B., Mittag, U., Eiken, O., Mekjavic, I. B., and Rittweger, J. (2018). Hypoxia aggravates inactivity-related muscle wasting. Front. Physiol. 9:494. doi: 10.3389/fphys.2018.00494

DerSimonian, R., and Laird, N. (1986). Meta-analysis in clinical trials. Control. Clin. Trials 7, 177-188. doi: 10.1016/0197-2456(86)90046-2

D’Hulst, G., and Deldicque, L. (2017). Human skeletal muscle wasting in hypoxia: a matter of hypoxic dose? J. Appl. Physiol. 122, 406-408. doi: 10.1152/ japplphysiol.00264.2016

Dill, D. B., Horvath, S. M., Dahms, T. E., Parker, R. E., and Lynch, J. R. (1969). Hemoconcentration at altitude. J. Appl. Physiol. 27, 514-518. doi: 10.1152/jappl. 1969.27.4.514

Egger, M., Davey Smith, G., Schneider, M., and Minder, C. (1997). Bias in metaanalysis detected by a simple, graphical test. BMJ 315, 629-634. doi: 10.1136/ bmj.315.7109.629

Ermolao, A., Bergamin, M., Rossi, A. C., Dalle Carbonare, L., and Zaccaria, M. (2011). Cardiopulmonary response and body composition changes after 
prolonged high altitude exposure in women. High Alt. Med. Biol. 12, 357-369. doi: 10.1089/ham.2010.1098

Favier, F. B., Britto, F. A., Freyssenet, D. G., Bigard, X. A., and Benoit, H. (2015). HIF-1-driven skeletal muscle adaptations to chronic hypoxia: molecular insights into muscle physiology. Cell. Mol. Life Sci. 72, 4681-4696. doi: 10.1007/ s00018-015-2025-9

Fulco, C. S., Cymerman, A., Pimental, N. A., Young, A. J., and Maher, J. T. (1985). Anthropometric changes at high altitude. Aviat. Space Environ. Med. $56,220-224$

Fulco, C. S., Friedlander, A. L., Muza, S. R., Rock, P. B., Robinson, S., Lammi, E., et al. (2002). Energy intake deficit and physical performance at altitude. Aviat. Space Environ. Med. 73, 758-765.

Fulco, C. S., Hoyt, R. W., Baker-Fulco, C. J., Gonzalez, J., and Cymerman, A. (1992). Use of bioelectrical impedance to assess body composition changes at high altitude. J. Appl. Physiol. 72, 2181-2187. doi: 10.1152/jappl.1992.72.6.2181

Fulco, C. S., Kambis, K. W., Friedlander, A. L., Rock, P. B., Muza, S. R., and Cymerman, A. (2005). Carbohydrate supplementation improves time-trial cycle performance during energy deficit at 4,300-m altitude. J. Appl. Physiol. 99, 867-876. doi: 10.1152/japplphysiol.00019.2005

Gatterer, H., Wille, M., Faulhaber, M., Lukaski, H., Melmer, A., Ebenbichler, C., et al. (2013). Association between body water status and acute mountain sickness. PLoS One 8:e73185. doi: 10.1371/journal.pone.0073185

Ge, R. L., Wood, H., Yang, H. H., Liu, Y. N., Wang, X. J., and Babb, T. (2010). The body weight loss during acute exposure to high-altitude hypoxia in sea level residents. Sheng Li Xue Bao 62, 541-546.

Greenleaf, J. E., Bernauer, E. M., Adams, W. C., and Juhos, L. (1978). Fluidelectrolyte shifts and VO2max in man at simulated altitude $(2,287 \mathrm{~m})$. J. Appl. Physiol. Respir. Environ. Exerc. Physiol. 44, 652-658. doi: 10.1152/jappl.1978.44. 5.652

Greie, S., Humpeler, E., Gunga, H. C., Koralewski, E., Klingler, A., Mittermayr, M., et al. (2006). Improvement of metabolic syndrome markers through altitude specific hiking vacations. J. Endocrinol. Invest. 29, 497-504. doi: 10.1007/ BF03344138

Greksa, L. P., Spielvogel, H., and Caceres, E. (1994). Total lung capacity in young highlanders of Aymara ancestry. Am. J. Phys. Anthropol. 94, 477-486. doi: 10.1002/ajpa.1330940404

Gunga, H. C., Fries, D., Humpeler, E., Kirsch, K., Boldt, L. E., Koralewski, E., et al. (2003). Austrian moderate altitude study (AMAS 2000) - fluid shifts, erythropoiesis, and angiogenesis in patients with metabolic syndrome at moderate altitude (congruent with 1700 m). Eur. J. Appl. Physiol. 88, 497-505. doi: 10.1007/s00421-002-0734-x

Hamad, N., and Travis, S. P. (2006). Weight loss at high altitude: pathophysiology and practical implications. Eur. J. Gastroenterol. Hepatol. 18, 5-10. doi: 10.1097/ 00042737-200601000-00002

Hannon, J. P., and Sudman, D. M. (1973). Basal metabolic and cardiovascular function of women during altitude acclimatization. J. Appl. Physiol. 34, 471-477. doi: 10.1152/jappl.1973.34.4.471

Heinonen, I. H., Boushel, R., and Kalliokoski, K. K. (2016). The circulatory and metabolic responses to hypoxia in humans - with special reference to adipose tissue physiology and obesity. Front. Endocrinol. 7:116. doi: 10.3389/fendo. 2016.00116

Higgins, J. P., and Thompson, S. G. (2004). Controlling the risk of spurious findings from meta-regression. Stat. Med. 23, 1663-1682. doi: 10.1002/sim.1752

Higgins, J. P., Thompson, S. G., Deeks, J. J., and Altman, D. G. (2003). Measuring inconsistency in meta-analyses. BMJ 327, 557-560. doi: 10.1136/bmj.327.741 4.557

Hill, N. E., Stacey, M. J., and Woods, D. R. (2011). Energy at high altitude. J. R. Army Med. Corps 157, 43-48. doi: 10.1136/jramc-157-01-08

Hobbins, L., Hunter, S., Gaoua, N., and Girard, O. (2017). Normobaric hypoxic conditioning to maximize weight loss and ameliorate cardio-metabolic health in obese populations: a systematic review. Am. J. Physiol. Regul. Integr. Comp. Physiol. 313, R251-R264. doi: 10.1152/ajpregu.00160.2017

Holm, L., Haslund, M. L., Robach, P., Van Hall, G., Calbet, J. A., Saltin, B., et al. (2010). Skeletal muscle myofibrillar and sarcoplasmic protein synthesis rates are affected differently by altitude-induced hypoxia in native lowlanders. PLoS One 5:e15606. doi: 10.1371/journal.pone.0015606

Hoppeler, H., Kleinert, E., Schlegel, C., Claassen, H., Howald, H., Kayar, S. R., et al. (1990). Morphological adaptations of human skeletal muscle to chronic hypoxia. Int. J. Sports Med. 11(Suppl. 1), S3-S9. doi: 10.1055/s-2007-102 4846

Hoyt, R. W., and Honig, A. (1996). "Body fluid and energy metabolism at high altitude," in Handbook of Physiology, eds C. M. Blatteis and M. J. Fregley (New York, NY: Oxford University Press), 1277-1289.

Hoyt, R. W., Jones, T. E., Baker-Fulco, C. J., Schoeller, D. A., Schoene, R. B., Schwartz, R. S., et al. (1994). Doubly labeled water measurement of human energy expenditure during exercise at high altitude. Am. J. Physiol. 266, R966R971. doi: 10.1152/ajpregu.1994.266.3.R966

Jacobs, R. A., Lundby, A. K., Fenk, S., Gehrig, S., Siebenmann, C., Fluck, D., et al. (2016). Twenty-eight days of exposure to $3454 \mathrm{~m}$ increases mitochondrial volume density in human skeletal muscle. J. Physiol. 594, 1151-1166. doi: 10. 1113/JP271118

Jung, R. C., Dill, D. B., Horton, R., and Horvath, S. M. (1971). Effects of age on plasma aldosterone levels and hemoconcentration at altitude. J. Appl. Physiol. 31, 593-597. doi: 10.1152/jappl.1971.31.4.593

Kamimori, G. H., Eddington, N. D., Hoyt, R. W., Fulco, C. S., Lugo, S., Durkot, M. J., et al. (1995). Effects of altitude $(4300 \mathrm{~m})$ on the pharmacokinetics of caffeine and cardio-green in humans. Eur. J. Clin. Pharmacol. 48, 167-170. doi: $10.1007 / \mathrm{BF} 00192744$

Kara, T., Narkiewicz, K., and Somers, V. K. (2003). Chemoreflexes-physiology and clinical implications. Acta Physiol. Scand. 177, 377-384. doi: 10.1046/j.1365201X.2003.01083.x

Kasprzak, Z., Sliwicka, E., Hennig, K., Pilaczynska-Szczesniak, L., HutaOsiecka, A., and Nowak, A. (2015). Vitamin D, iron metabolism, and diet in alpinists during a 2-week high-altitude climb. High Alt. Med. Biol. 16, 230-235. doi: 10.1089/ham.2015.0008

Kayser, B. (1994). Nutrition and energetics of exercise at altitude. Theory and possible practical implications. Sports Med. 17, 309-323. doi: 10.2165/ 00007256-199417050-00004

Kayser, B., Acheson, K., Decombaz, J., Fern, E., and Cerretelli, P. (1992). Protein absorption and energy digestibility at high altitude. J. Appl. Physiol. 73, 24252431. doi: 10.1152/jappl.1992.73.6.2425

Kayser, B., Narici, M., Milesi, S., Grassi, B., and Cerretelli, P. (1993). Body composition and maximum alactic anaerobic performance during a one month stay at high altitude. Int. J. Sports Med. 14, 244-247. doi: 10.1055/s-20071021171

Kayser, B., and Verges, S. (2013). Hypoxia, energy balance and obesity: from pathophysiological mechanisms to new treatment strategies. Obes. Rev. 14, 579-592. doi: 10.1111/obr.12034

Ledderhos, C., Pongratz, H., Exner, J., Gens, A., Roloff, D., and Honig, A. (2002). Reduced tolerance of simulated altitude $(4200 \mathrm{~m})$ in young men with borderline hypertension. Aviat. Space Environ. Med. 73, 1063-1066.

Levett, D. Z., Radford, E. J., Menassa, D. A., Graber, E. F., Morash, A. J., Hoppeler, H., et al. (2012). Acclimatization of skeletal muscle mitochondria to high-altitude hypoxia during an ascent of Everest. FASEB J. 26, 1431-1441. doi: 10.1096/fj.11-197772

Lippl, F. J., Neubauer, S., Schipfer, S., Lichter, N., Tufman, A., Otto, B., et al. (2010). Hypobaric hypoxia causes body weight reduction in obese subjects. Obesity 18 , 675-681. doi: 10.1038/oby.2009.509

Lundby, C., Pilegaard, H., Andersen, J. L., van Hall, G., Sander, M., and Calbet, J. A. L. (2004). Acclimatization to $4100 \mathrm{~m}$ does not change capillary density or mRNA expression of potential angiogenesis regulatory factors in human skeletal muscle. J. Exp. Biol. 207, 3865-3871. doi: 10.1242/jeb. 01225

Matu, J., Deighton, K., Ispoglou, T., and Duckworth, L. (2017). The effect of moderate versus severe simulated altitude on appetite, gut hormones, energy intake and substrate oxidation in men. Appetite 113, 284-292. doi: 10.1016/j. appet.2017.02.041

Matu, J., Gonzalez, J. T., Ispoglou, T., Duckworth, L., and Deighton, K. (2018). The effects of hypoxia on hunger perceptions, appetite-related hormone concentrations and energy intake: a systematic review and meta-analysis. Appetite 125, 98-108. doi: 10.1016/j.appet.2018.01.015

Mawson, J. T., Braun, B., Rock, P. B., Moore, L. G., Mazzeo, R., and Butterfield, G. E. (2000). Women at altitude: energy requirement at 4,300 m. J. Appl. Physiol. 88, 272-281. doi: 10.1152/jappl.2000.88.1.272

Mekjavic, I. B., Amon, M., Kolegard, R., Kounalakis, S. N., Simpson, L., Eiken, O., et al. (2016). The effect of normobaric hypoxic confinement on metabolism, 
gut hormones, and body composition. Front. Physiol. 7:202. doi: 10.3389/fphys. 2016.00202

Mizuno, M., Savard, G. K., Areskog, N. H., Lundby, C., and Saltin, B. (2008). Skeletal muscle adaptations to prolonged exposure to extreme altitude: a role of physical activity? High Alt. Med. Biol. 9, 311-317. doi: 10.1089/ham.2008.1009

Murray, A. J. (2009). Metabolic adaptation of skeletal muscle to high altitude hypoxia: how new technologies could resolve the controversies. Genome Med. 1:117. doi: $10.1186 / \mathrm{gm} 117$

Ocobock, C. J. (2017). Body fat attenuates muscle mass catabolism among physically active humans in temperate and cold high altitude environments. Am. J. Hum. Biol. 29:e23013. doi: 10.1002/ajhb.23013

Pasiakos, S. M., Berryman, C. E., Carrigan, C. T., Young, A. J., and Carbone, J. W. (2017). Muscle protein turnover and the molecular regulation of muscle mass during hypoxia. Med. Sci. Sports Exerc. 49, 1340-1350. doi: 10.1249/MSS. 0000000000001228

Pulfrey, S. M., and Jones, P. J. (1996). Energy expenditure and requirement while climbing above 6,000 m. J. Appl. Physiol. 81, 1306-1311. doi: 10.1152/jappl. 1996.81.3.1306

Reynolds, R. D., Lickteig, J. A., Deuster, P. A., Howard, M. P., Conway, J. M., Pietersma, A., et al. (1999). Energy metabolism increases and regional body fat decreases while regional muscle mass is spared in humans climbing Mt. Everest. J. Nutr. 129, 1307-1314. doi: 10.1093/jn/129.7.1307

Rolfe, D. F., and Brown, G. C. (1997). Cellular energy utilization and molecular origin of standard metabolic rate in mammals. Physiol. Rev. 77, 731-758. doi: 10.1152/physrev.1997.77.3.731

Rose, M. S., Houston, C. S., Fulco, C. S., Coates, G., Sutton, J. R., and Cymerman, A. (1988). Operation Everest. II: nutrition and body composition. J. Appl. Physiol. 65, 2545-2551. doi: 10.1152/jappl.1988.65.6.2545

Savourey, G., Garcia, N., Besnard, Y., Hanniquet, A. M., Fine, M. O., and Bittel, J. (1994). Physiological changes induced by pre-adaptation to high altitude. Eur. J. Appl. Physiol. Occup. Physiol. 69, 221-227. doi: 10.1007/BF01094792

Schena, F., Guerrini, F., Tregnaghi, P., and Kayser, B. (1992). Branched-chain amino acid supplementation during trekking at high altitude. The effects on loss of body mass, body composition, and muscle power. Eur. J. Appl. Physiol. Occup. Physiol. 65, 394-398. doi: 10.1007/BF00243503

Shukla, V., Singh, S. N., Vats, P., Singh, V. K., Singh, S. B., and Banerjee, P. K. (2005). Ghrelin and leptin levels of sojourners and acclimatized lowlanders at high altitude. Nutr. Neurosci. 8, 161-165. doi: 10.1080/10284150500132823

Siebenmann, C., Robach, P., and Lundby, C. (2017). Regulation of blood volume in lowlanders exposed to high altitude. J. Appl. Physiol. 123, 957-966. doi: 10.1152/japplphysiol.00118.2017

Smith, J. D., Cianflone, K., Martin, J., Poirier, P., Broderick, T. L., and Noel, M. (2011). Plasma adipokine and hormone changes in mountaineers on ascent to 5300 meters. Wilderness Environ. Med. 22, 107-114. doi: 10.1016/j.wem.2011. 01.003

Stock, M. J., Norgan, N. G., Ferro-Luzzi, A., and Evans, E. (1978). Effect of altitude on dietary-induced thermogenesis at rest and during light exercise in man. J. Appl. Physiol. Respir. Environ. Exerc. Physiol. 45, 345-349.

Subudhi, A. W., Bourdillon, N., Bucher, J., Davis, C., Elliott, J. E., Eutermoster, M., et al. (2014). AltitudeOmics: the integrative physiology of human acclimatization to hypobaric hypoxia and its retention upon reascent. PLoS One 9:e92191. doi: 10.1371/journal.pone.0092191

Surks, M. I., Chinn, K. S., and Matoush, L. R. (1966). Alterations in body composition in man after acute exposure to high altitude. J. Appl. Physiol. 21, 1741-1746. doi: 10.1152/jappl.1966.21.6.1741

Swenson, E., and Bärtsch, P. (2014). High Altitude: Human Adaptation to Hypoxia. New York, NY: Springer. doi: 10.1007/978-1-4614-8772-2
Tam, E., Bruseghini, P., Calabria, E., Dal Sacco, L., Doria, C., Grassi, B., et al., (2016). Gokyo Khumbu/Ama Dablam Trek 2012: effects of physical training and high-altitude exposure on oxidative metabolism, muscle composition, and metabolic cost of walking in women. Eur. J. Appl. Physiol. 116, 129-144. doi: 10.1007/s00421-015-3256-z

Tanner, D. A., and Stager, J. M. (1998). Partitioned weight loss and body composition changes during a mountaineering expedition: a field study. Wilderness Environ. Med. 9, 143-152.

Thompson, S. G., and Higgins, J. P. (2002). How should meta-regression analyses be undertaken and interpreted? Stat. Med. 21, 1559-1573.

Vats, P., Singh, V. K., Singh, S. N., and Singh, S. B. (2007). High altitude induced anorexia: effect of changes in leptin and oxidative stress levels. Nutr. Neurosci. 10, 243-249. doi: 10.1080/10284150701722299

Watt, E. W., Picon-Reategui, E., Gahagan, H. E., and Buskirk, E. R. (1976). Dietary intake and coronary risk factors in Peruvian Quechua Indians. J. Am. Diet. Assoc. 68, 535-537.

Westerterp, K. R., and Kayser, B. (2006). Body mass regulation at altitude. Eur. J. Gastroenterol. Hepatol. 18, 1-3. doi: 10.1097/00042737-20060100000001

Westerterp, K. R., Kayser, B., Brouns, F., Herry, J. P., and Saris, W. H. (1992). Energy expenditure climbing Mt. Everest. J. Appl. Physiol. 73, 1815-1819. doi: 10.1152/jappl.1992.73.5.1815

Westerterp, K. R., Kayser, B., Wouters, L., Le Trong, J. L., and Richalet, J. P. (1994). Energy balance at high altitude of 6,542 m. J. Appl. Physiol. 77, 862-866. doi: 10.1152/jappl.1994.77.2.862

Westerterp-Plantenga, M. S., Westerterp, K. R., Rubbens, M., Verwegen, C. R., Richelet, J. P., and Gardette, B. (1999). Appetite at "high altitude" [Operation Everest III (Comex-'97)]: a simulated ascent of Mount Everest. J. Appl. Physiol. 87, 391-399. doi: 10.1152/jappl.1999.87.1.391

Wing-Gaia, S. L., Gershenoff, D. C., Drummond, M. J., and Askew, E. W. (2014). Effect of leucine supplementation on fat free mass with prolonged hypoxic exposure during a 13-day trek to Everest Base Camp: a double-blind randomized study. Appl. Physiol. Nutr. Metab. 39, 318-323. doi: 10.1139/apnm2013-0319

Wolfel, E. E., Groves, B. M., Brooks, G. A., Butterfield, G. E., Mazzeo, R. S., Moore, L. G., et al. (1991). Oxygen transport during steady-state submaximal exercise in chronic hypoxia. J. Appl. Physiol. 70, 1129-1136. doi: 10.1152/jappl.1991.70. 3.1129

Workman, C., and Basset, F. A. (2012). Post-metabolic response to passive normobaric hypoxic exposure in sedendary overweight males: a pilot study. Nutr. Metab. 9:103. doi: 10.1186/1743-7075-9-103

Zamboni, M., Armellini, F., Turcato, E., Robbi, R., Micciolo, R., Todesco, T., et al. (1996). Effect of altitude on body composition during mountaineering expeditions: interrelationships with changes in dietary habits. Ann. Nutr. Metab. 40, 315-324. doi: 10.1159/000177931

Conflict of Interest Statement: The authors declare that the research was conducted in the absence of any commercial or financial relationships that could be construed as a potential conflict of interest.

Copyright (c) 2019 Dünnwald, Gatterer, Faulhaber, Arvandi and Schobersberger. This is an open-access article distributed under the terms of the Creative Commons Attribution License (CC BY). The use, distribution or reproduction in other forums is permitted, provided the original author(s) and the copyright owner(s) are credited and that the original publication in this journal is cited, in accordance with accepted academic practice. No use, distribution or reproduction is permitted which does not comply with these terms. 